\title{
New Mode (Molecular-Sensing) of Heinz Body Formation Mechanisms Inherent in Human Erythrocytes: Basis for Understanding of Clinical Aspects of Drug-Induced Hemolytic Anemia and the Like
} Yoshiaki Sugawara*, Yuki Shigemasa, Yuko Hayashi, Yoko Abe, Ikumi Ohgushi and Eriko Ueno

Department of Health Science, Prefectural University of Hiroshima, Hiroshima 734-8558, Japan

\begin{abstract}
The human hemoglobin $(\mathrm{Hb})$ molecule $\left(\alpha_{2} \beta_{2}\right)$ has two types of $\alpha-\beta$ interface (i.e., $\alpha_{1}-\beta_{1}$ [and $\alpha_{2}-\beta_{2}$ ] and $\alpha_{1}-\beta_{2}$ [and $\left.\left.\alpha_{2}-\beta_{1}\right]\right)$. The latter $\alpha_{1}-\beta_{2}\left(\right.$ and $\left.\alpha_{2}-\beta_{1}\right)$ interface is associated with cooperative $O_{2}$ binding, and exhibits principal roles if the molecule goes from its deoxygenated to oxygenated quaternary structure. The role of the former $\alpha_{1}-\beta_{1}($ and $\alpha_{2}-\beta_{2}$ ) interface has been unclear for a long time. In this regard, important and intriguing observations have been accumulating, so that a new gaze can be focused on the $\alpha_{1}-\beta_{1}$ (and $\alpha_{2}-\beta_{2}$ ) interface. Our most recent findings suggest that the $\alpha_{1}-\beta_{1}$ (and $\alpha_{2}-\beta_{2}$ ) interface may exert delicate control of the intrinsic tilting capability of the distal (E7) His residues (i.e., $\alpha 58 \mathrm{His}(\mathrm{E} 7)$ in the $\alpha$ chain and $\beta 63 \mathrm{His}$ (E7) in the $\beta$ chain) depending on internal and external conditions of the erythrocyte to lead to degradation of $\mathrm{Hb}$ to hemichrome, and subsequent clustering of Heinz bodies within the erythrocyte. In the spleen, rigid intra-erythrocytic hemichrome inclusions (Heinz bodies) act as "sticking points", so Heinz body-containing red cells become trapped and undergo hemolysis. In this article, we first provide our necessary basic experimental findings that led us to grasp molecular biosensing mechanisms inherent in human erythrocytes for the appreciation of aging and determination of their lifespan, and summarize their roles in physiology. We then discuss how these accomplishments contribute to deeper understanding of clinical aspects of drug-induced hemolytic anemia, defects in the intra-erythrocytic reducing system and unstable $\mathrm{Hb}$ disease, in which the mechanisms for acute hemolytic crisis cannot be explained on the basis of conventional views.
\end{abstract}

Keywords: Red cell aging; Hemichrome formation; Heinz-body clustering; Drug-induced hemolytic anemia; Defects in the intraerythrocytic reducing system; Unstable hemoglobin disease

\section{Introduction}

Human red blood corpuscles survive in the circulation for an average of 120 days. Removal of aged and damaged red cells from the blood circulation is essential for its homeostasis. How do human erythrocytes appreciate aging and determine their lifespan? In a series of studies, we have attempted to examine the relationship between the oxidative behavior of human hemoglobin $(\mathrm{Hb})$ molecules (i.e., oxidation of $\mathrm{HbO}_{2}$ by the bound $\mathrm{O}_{2}$ to the ferric met-form), hemichrome emergence and the formation of Heinz bodies within the erythrocytes.

Heinz bodies are intra-erythrocytic inclusions of hemichrome formed from oxidized or denatured hemoglobin $(\mathrm{Hb})$. Heinz bodies are typically formed in aged red cells [1]. However, they are rarely mentioned in the context of normal $\mathrm{Hb}$ or normal erythrocytes. Heinz bodies have been characterized in drug-induced hemolytic anemia, defects in the intra-erythrocytic reducing system (e.g., glucose 6-phosphate dehydrogenase [G-6-PD] deficiency) and in unstable $\mathrm{Hb}$ disease $[2,3]$. Nevertheless, Heinz bodies in normal erythrocytes are of interest because they (or their related intra-erythrocytic inclusions) are involved in the recognition mechanisms in the spleen responsible for the removal of non-functional erythrocytes from the circulation. The rigid intra-erythrocytichemichrome inclusions are known to act as "sticking points", and hence Heinz body-containing red cells become trapped and undergo hemolysis [4].

Hemichrome is rarely found in erythrocytes in situ, even though the reaction dynamics of $\mathrm{Hb}$ with molecular oxygen $\left(\mathrm{O}_{2}\right)$ make them particularly suitable $\mathrm{O}_{2}$ carriers. $\mathrm{Hb}$ can bind $\mathrm{O}_{2}$ in the ferrous state to carry out its physiological functions. During this reversible binding of $\mathrm{O}_{2}$, the oxygenated form of $\mathrm{Hb}\left(\mathrm{HbO}_{2}\right)$ is known to be oxidized by the bound $\mathrm{O}_{2}$ to the ferric met form (metHb), which cannot be oxygenated, and is thus physiologically inactive. The resultant met $\mathrm{Hb}$ is reduced back to the ferrous state by an intra-erythrocyticnicotinamide adenine dinucleotide (NADH)-dependent reducing system [5-7]. However, it has been suggested that its oxidation (autoxidation) can be followed by transformation of the oxidized molecule (high-spin $\mathrm{Fe}^{3+}$ ) into a species absorbing as a low-spin compound, i.e., hemichrome, the formation of which can result in the accumulation of soluble and insoluble hemichromes as well as precipitation [8-13]. Despite these findings, direct evidence of hemichrome formation in normal erythrocytes is lacking.

Compared with the tetrameric parent $\mathrm{Hb}$, hemichrome formation is enhanced in separated $\alpha$ and $\beta$ chains [8,13-16]. Following the method of Brunori et al. [14], our ultraviolet/visible (UV/VIS) spectroscopic study [17] showed that human adult $\mathrm{Hb}\left(\mathrm{HbAO}_{2}\right.$ or simply designated as $\mathrm{HbO}_{2}$ ) from healthy donors tended to degrade to produce hemichrome even at close-to-physiological temperatures and $\mathrm{pH}$. However, its occurrence was a function of $\mathrm{pH}$, temperature and the progress of autoxidation of ferrous $\mathrm{HbO}_{2}$ to the ferric met form through oxidation by bound $\mathrm{O}_{2}$.

*Corresponding author: Yoshiaki Sugawara, Department of Health Science Prefectural University of Hiroshima, Hiroshima 734-8558, Japan, Tel: +81-82-2519783; Fax: +81-82-251-9405; E-mail: sugawara@pu-hiroshima.ac.jp

Received May 02, 2013; Accepted June 12, 2013; Published June 15, 2013

Citation: Sugawara Y, Shigemasa Y, Hayashi Y, Abe Y, Ohgushi I, et al. (2013) New Mode (Molecular-Sensing) of Heinz Body Formation Mechanisms Inherent in Human Erythrocytes: Basis for Understanding of Clinical Aspects of Drug-Induced Hemolytic Anemia and the Like. J Bioanal Biomed 5: 036-056. doi:10.4172/1948593X.1000078

Copyright: (c) 2013 Sugawara Y, et al. This is an open-access article distributed under the terms of the Creative Commons Attribution License, which permits unrestricted use, distribution, and reproduction in any medium, provided the original author and source are credited. 
Citation: Sugawara Y, Shigemasa Y, Hayashi Y, Abe Y, Ohgushi I, et al. (2013) New Mode (Molecular-Sensing) of Heinz Body Formation Mechanisms Inherent in Human Erythrocytes: Basis for Understanding of Clinical Aspects of Drug-Induced Hemolytic Anemia and the Like. J Bioanal Biomed 5: 036-056. doi:10.4172/1948-593X.1000078

Cellular life is reliant upon rapid and efficient responses to internal and external conditions. The basic molecular events associated with these processes are the structural transitions of the proteins involved [18]. Therefore, understanding of the structural basis of protein allostery is of paramount importance to characterize these processes. The human $\mathrm{Hb}$ molecule ( $\alpha_{2} \beta$; alternatively, a dimer of $\alpha \beta$ protomers), whose $\alpha$ and $\beta$ chains contain 141 and 146 amino-acid residues, respectively, holds a special position in these structural transitions. This is due to the achievements of Perutz, whose pioneering studies led to the identification of two distinct $\mathrm{Hb}$ structures, the tense $(\mathrm{T})$ and relaxed (R) state, which are associated with the deoxygenated and oxygenated form of the protein, respectively [19-21]. Hb has two types of $\alpha \beta$ interface (i.e., $\alpha_{1} \beta_{1}$ [and $\alpha_{2} \beta_{2}$ ] and $\alpha_{1} \beta_{2}$ [and $\alpha_{2} \beta_{1}$ ]). The latter $\alpha_{1}-\beta_{2}$ (and $\alpha_{2}-\beta_{1}$ ) interface is known to be associated with cooperative dioxygen $\left(\mathrm{O}_{2}\right)$ binding, and exhibits important roles if the molecule goes from its deoxygenated to the oxygenated quaternary structure. However, the role of the former $\alpha_{1}-\beta_{1}$ (and $\alpha_{2}-\beta_{2}$ ) interface has been unclear for a long time.

A representative set of successive $\mathrm{O}_{2}$-binding constants regarding human $\mathrm{Hb}$ is given in terms of $\mathrm{mmHg}^{-1}$ as follows: $K_{1}=0.0188, K_{2}=$ $0.0566, K_{3}=0.407, K_{4}=4.28$ in $0.1 \mathrm{M}$ buffer $(\mathrm{pH} 7.4)$ containing 0.1 $\mathrm{M} \mathrm{KCl}$ at $25^{\circ} \mathrm{C}$ [22]. In this reaction, by comparing their X-ray crystal structures, major differences have been defined between deoxygenated and oxygenated forms. These include: movement of the iron atom into the heme plane with a simultaneous change in the orientation of the proximal (F8) His; rotation of the $\alpha_{1} \beta_{1}$ dimer relative to the other $\alpha_{2} \beta_{2}$ dimer about an axis $P$ by $12-15^{\circ}$; and a translation of one dimer relative to the other along the $\mathrm{P}$ axis by $\sim 1 \AA\left(10^{-1} \mathrm{~nm}\right)$. These changes are accompanied by sequential breaking of "salt bridges" by C-terminal residues [23-27]. When $\mathrm{HbO}_{2}$ goes from the deoxygenated to the oxygenated quaternary structure, the $\alpha_{1}-\beta_{2}$ (and $\alpha_{2}-\beta_{1}$ ) interface undergoes the principal changes associated with cooperative oxygen binding, so it is named the "sliding contact" that involves 19 residues, including mainly helices $\mathrm{C}$ and $\mathrm{H}$ and the FG corner [25,28].

Conversely, negligible changes are found with respect to the crystal structure examined for the $\alpha_{1}-\beta_{1}$ (and $\alpha_{2}-\beta_{2}$ ) interface that associates 35 residues including $B, G$, and $H$ helices as well as the $\mathrm{GH}$ corner. Understanding of subunit interactions between the four $\mathrm{Hb}$ chains (and how these explain cooperative $\mathrm{O}_{2}$ binding) has been the primary focus in $\mathrm{Hb}$ research. This has been coupled with a tendency for structural analyses to focus on the changes at the proximal side of the heme and at the $\alpha_{1}-\beta_{2}$ (and $\alpha_{2}-\beta_{1}$ ) interface, as mentioned above. This is despite the fact that the configuration of the residues lining the distal side of the heme pocket (where molecular $\mathrm{O}_{2}$ binds) are also altered by oxygenation, and are thought to have a role in controlling access of the ligand to the heme pocket [29]. Hence, the possibility of subunit interactions originating from or being transmitted via distal side effects has, for the most part, been neglected.

In this regard, important and intriguing observations have been accumulating while paying attention to the $\alpha_{1}-\beta_{1}$ (and $\alpha_{2}-\beta_{2}$ ) interface as well as distal-side perturbations. Hence, a new gaze could be focused on the $\alpha_{1}-\beta_{1}$ (and $\alpha_{2}-\beta_{2}$ ) interface and the distal-side perturbations of the heme pocket. With respect to the $\alpha_{1}-\beta_{1}$ (and $\alpha_{2}-\beta_{2}$ ) interface, a new role has been attributed to stabilizing the $\mathrm{HbO}_{2}$ tetramer against acidic autoxidation. That is, the $\alpha_{1}-\beta_{1}$ (and $\alpha_{2}-\beta_{2}$ ) interface produces a conformational constraint in the $\beta$ chain whereby the distal (E7) histidine (His) residue is tilted slightly away from the bound $\mathrm{O}_{2}$ so as to prevent proton-catalyzed displacement of $\mathrm{O}_{2}{ }^{-}$by a solvent water molecule [30,31]. The $\beta$ chains thus acquire $\mathrm{pH}$-dependent delayed autoxidation in the $\mathrm{HbO}_{2}$ tetramer. The next role was suggested by our studies searching for similar phenomena in normal human erythrocytes under mild heating $[17,32,33]$. It seemed that tilting of the distal (E7) His in turn triggers degradation of the $\mathrm{Hb}$ molecule to hemichrome, and subsequent clustering of Heinzbodies within the erythrocyte. In the spleen, Heinz body-containing red cells become trapped while traversing small apertures in the basement membranes separating the cords from the sinusoids (where the spaces are sufficiently small to require extreme deformation of red cells) and undergo hemolysis [4]. Thus, it was suggested that the $\mathrm{Hb}$ molecule controls removal of erythrocytes from the blood circulation by triggering degradation of the $\mathrm{Hb}$ molecule to hemichrome, and subsequent clustering of Heinz bodies within the erythrocytes depending on the internal and extraneous conditions of the erythrocyte (including $\mathrm{pH}$ and temperature). Hence, in our recent publication [34], we reviewed and summarized current interpretations of the oxidative behavior of human $\mathrm{Hb}$ and the related results. We emphasized the correlation between hemichrome emergence and the formation of Heinz bodies within the erythrocytes. In relevance to a clinical aspect, we also suggested that a quite large number of unstable $\mathrm{Hbs}$ are resulted from substitutions affecting on the $\beta$ chain, especially in the $\alpha_{1}-\beta_{1}$ (and $\alpha_{2}-\beta_{2}$ ) interface including B, G, and $\mathrm{H}$ helices: Tacoma [ $\beta 30(\mathrm{~B} 12) \mathrm{Arg} \rightarrow$ Ser], Abraham Lincoln [ $\beta 32(B 14)$ Leu $\rightarrow$ Pro], Peterborough $[\beta 111(G 13)$ Val $\rightarrow$ Phe], Madrid [ $\beta 115(G 17)$ Ala $\rightarrow$ Pro], J. Guantanamo [ $\beta 128(H 6)$ Ala $\rightarrow$ Asp], Leslie $[\beta 131(\mathrm{H} 9) \mathrm{Gln} \rightarrow$ deleted] and so on.

In this article, we first provide an overview of our necessary basic analytical and bioanalytical methods and their findings that led us to grasp molecular biosensing mechanisms inherent in human erythrocytes for the appreciation of aging and determination of their lifespan, and summarize their roles in physiology, whereby the intrinsic tilting capability of distal (E7) His residues (their bis-histidyl coordination proficiency to the heme iron) and the $\alpha_{1}-\beta_{1}$ (and $\alpha_{2}-\beta_{2}$ ) interface of the $\mathrm{Hb}$ molecule has major responsibility. Along with these lines of accomplishments and by integrating the most recent state of $\mathrm{Hb}$ research, we attempt to form a new mode of Heinz body formation mechanisms, in which built-in sensors in $\mathrm{Hb}$ molecule (i.e., bis-histidyl coordination proficiency of distal (E7) His residues and the $\alpha_{1}-\beta_{1}$ (and $\alpha_{2}-\beta_{2}$ ) interface) can control degradation of the $\mathrm{Hb}$ molecule to hemichrome depending on internal and external conditions in the erythrocyte, and subsequent clustering of Heinz bodies within the erythrocyte. Granting this new mode (molecular sensing) of Heinz body formation mechanisms to be basic premise, we then examine how these new views contribute to deeper understanding of clinical aspects of hemoglobinopathies and hemolytic anemia and its associated acute blood loss, in which the mechanisms for acute hemolytic crisis cannot be explained on the basis of conventional views.

\section{Experimental Accomplishments}

\section{Hemichrome formation (Degradation of the $\mathrm{Hb}$ molecule to Hemichrome) observed in Human $\mathrm{Hb}\left(\mathrm{HbO}_{2}\right)$ even at physiological $\mathrm{pH}$ and temperature: UV/VIS spectroscopic observations}

The dynamics of the reaction of human $\mathrm{Hb}$ with $\mathrm{O}_{2}$ provide them particularly suitable $\mathrm{O}_{2}$ carriers. In the $\mathrm{O}_{2}$ binding process of $\mathrm{Hb}$, the iron remains in the ferrous state so that the reaction is an oxygenation, not an oxidation. However, once the molecule is oxygenated, the resultant species $\left(\mathrm{HbO}_{2}\right)$ must undergo oxidation by the bound $\mathrm{O}_{2}$ to 
Citation: Sugawara Y, Shigemasa Y, Hayashi Y, Abe Y, Ohgushi I, et al. (2013) New Mode (Molecular-Sensing) of Heinz Body Formation Mechanisms Inherent in Human Erythrocytes: Basis for Understanding of Clinical Aspects of Drug-Induced Hemolytic Anemia and the Like. J Bioanal Biomed 5: 036-056. doi:10.4172/1948-593X.1000078

the ferric met-form. If $\mathrm{HbO}_{2}$ is oxidized (autoxidized), the product (ferric metHb) cannot be oxygenated in its present form.

In this regard, it has been suggested that the autoxidation process of $\mathrm{Hb}$ may be associated with transformation of the oxidized molecule (high-spin $\mathrm{Fe}^{3+}$ ) into hemichrome, the formation of which can result in the accumulation of soluble and insoluble hemichromes as well as precipitation [8-13]. Formation of hemichrome is known to be enhanced in separated $\alpha$ and $\beta$ chains [9,13-17]. So, we deal first the innate molecular instability of $\mathrm{Hb}$, which triggers degradation of the molecule to hemichrome. This process is detected readily through UV/ VIS spectroscopic observation during the entire process of autoxidation of human $\mathrm{HbO}_{2}$ [17].

$\mathrm{HbO}_{2}$ was prepared from freshly drawn samples of human blood (total, 50-80 mL) obtained from healthy donors. The details can be referred to Sugawara et al. (1993) [35]. The autoxidation of $\mathrm{HbO}_{2}$ was measured by UV/VIS spectroscopic means in $0.1 \mathrm{M}$ buffer over a wide $\mathrm{pH}$ range $(5.3-10.5)$ at $37^{\circ} \mathrm{C}$. Two milliliters of solution containing $0.2 \mathrm{M}$ buffer was placed in a test tube and incubated in a water bath maintained at $37 \pm 0.1^{\circ} \mathrm{C}$ using a NESLAB temperature control system (Model RTE-100 or 111 or 210; NESLAB Instruments, Inc., Portsmouth, NH, USA). The reaction was started by adding the same volume of fresh $\mathrm{HbO}_{2}$ solution (50-125 $\mu \mathrm{M}$ in heme contents). The reaction mixture was then quickly transferred to a spectrophotometric cell (Spectrocell, Type Inject-A-Cell; Funakoshi Co., Tokyo, Japan) with a screwcap stopper. Changes in absorption at $450-650 \mathrm{~nm}$ were recorded on the same chart at measured time intervals. Spectra were recorded using an UV/VIS spectrophotometer (JASCO, Model Ubest-50 or V-560 or V-570; Japan Spectroscopic Co., Tokyo, Japan), equipped with a thermostatically controlled (within $\pm 0.1^{\circ} \mathrm{C}$ ) cell holder. At the final state of each run, $\mathrm{Hb}$ molecules were all completely converted to the ferric met form by addition of potassium ferricyanide. The buffers used were: acetate for $\mathrm{pH} 4.5-5.5,2-(\mathrm{N}$-morpholino $)$ ethanesulfonic acid monohydrate (MES) for $\mathrm{pH}$ 5.0-6.75, N-2hydroxyethylpiperazine-N'-2-ethanesulfonic acid (HEPES) for $\mathrm{pH}$ 6.55-8.3, 2-(cyclohexylamino) ethanesulfonic acid (CHES) for $\mathrm{pH} 8.2$ 10.2, and 3-cyclohexylaminopropanesulfonic acid for $\mathrm{pH}$ 10.0-10.5.

Figure 1 indicates how autoxidation is inseparably related to the instability of the $\mathrm{Hb}$ molecule and its degradation to hemichrome. Figure 1a shows the spectrophotometric changes over time from 450 $\mathrm{nm}$ to $650 \mathrm{~nm}$ when fresh $\mathrm{HbO}_{2}$ was placed in $0.1 \mathrm{M} \mathrm{MES} \mathrm{buffer} \mathrm{(} \mathrm{pH}$ 5.0 ) at $37^{\circ} \mathrm{C} . \mathrm{HbO}_{2}$ was autoxidized to its ferric met form (metHb) without showing any hemichrome formation during the entire process. Contrary to this, the situations demonstrated in Figures 1b-1d are very different. Figure $1 \mathrm{~b}$ illustrates the observed UV/VIS spectra with time for hemichrome formation during autoxidation of $\mathrm{HbO}_{2}$ when $\mathrm{HbO}_{2}$ was incubated in $0.1 \mathrm{M}$ MES buffer $\left(\mathrm{pH} 6.5\right.$ ) at $40^{\circ} \mathrm{C}$. $\mathrm{HbO}_{2}$ was autoxidized to its ferric met form. However, sudden disruption of the spectra was observed during the late stage of the reaction whereby hemichrome formation could bedetected by elevation of the baseline and a shift in isosbestic points caused by precipitation. Similarly it took place at the intermediate stage in $0.1 \mathrm{M}$ HEPES buffer $(\mathrm{pH} 8.0)$ at $40^{\circ} \mathrm{C}$ in the case of Figure 1c, while at the initial stage in the case of Figure 1d in which immediately after fresh $\mathrm{HbO}_{2}$ was transfer to the cuvette in 0.1 M HEPES buffer ( $\mathrm{pH} 7.0$ ) at $45^{\circ} \mathrm{C}$.

In brief, occurrence of $\mathrm{pH}$ - and temperature-dependent hemichrome formation could be readily detected in $\mathrm{HbO}_{2}$ at every stage during the course of autoxidation (i.e., during the initial, intermediate, and final stages) while varying the temperature of the solution from $35^{\circ} \mathrm{C}$ to $55^{\circ} \mathrm{C}$ and the $\mathrm{pH}$ from 4.5 to 10.5 . In Figure $2 \mathrm{a}$,we therefore attempted to categorize the phenomenon into the following four cases in terms of $\left[\mathrm{HbO}_{2}\right]_{t=E . P .} /\left[\mathrm{HbO}_{2}\right]_{0}$, as itsemergence was a function of not only the $\mathrm{pH}$ and temperature of the solution, but also of the progress of the autoxidation of $\mathrm{HbO}_{2}$ :

(1) $t=0$ or $\left[\mathrm{HbO}_{2}\right]_{t=E . P .} /\left[\mathrm{HbO}_{2}\right]_{0}=1 \leq \mathrm{t}_{\text {E.P. }}<\left[\mathrm{HbO}_{2}\right]_{t=E . P .} /\left[\mathrm{HbO}_{2}\right]_{0}$ $=0.75$;

(2) $\left[\mathrm{HbO}_{2}\right]_{t=E . P .} /\left[\mathrm{HbO}_{2}\right]_{0}=0.75 \leq \mathrm{t}_{\mathrm{E.P}}<\left[\mathrm{HbO}_{2}\right]_{t=E . P .} /\left[\mathrm{HbO}_{2}\right]_{0}=0.25 ;$

(3) $\mathrm{t}_{\text {E.P. }} \leq\left[\mathrm{HbO}_{2}\right]_{t=\text { E.P. }} /\left[\mathrm{HbO}_{2}\right]_{0}=0.25$;

(4) no hemichrome formation during the entire process.

Here E.P. is the observed emergence point of hemichrome formation in each run. $\left[\mathrm{HbO}_{2} t=E\right.$ E.P. $/\left[\mathrm{HbO}_{2}\right]_{0}$ is the ratio of $\mathrm{HbO}_{2}$ concentration after time $t=E$.P. to that at time $t=0$ and can be monitored by the absorbance ratio of $\left(\mathrm{A}_{t}-\mathrm{A}_{\infty}\right) /\left(\mathrm{A}_{0}-\mathrm{A}_{\infty}\right)$ at 576 $\mathrm{nm}\left(\alpha\right.$-peak of $\left.\mathrm{HbO}_{2}\right)$. $\left[\mathrm{HbO}_{2}\right]_{t=E P} /\left[\mathrm{HbO}_{2}\right]_{0}=0.5$ represents equal mixtures of $\mathrm{HbO}_{2}$ and metHb, i.e., the midpoint of the autoxidation reaction. Hence, case (1) means that hemichrome formation was noticeable at the initial stage of autoxidation. Accordingly, case (2) indicates its occurrence at the intermediate stage, and case (3) at the final stage. In Figure 2a, the symbols used correspond to: for case (1), $\boldsymbol{\Delta}$ for case (2), $\triangle$ for case (3) and $\bigcirc$ for case (4). To determine if the phenomenon was represented by case (3) or case (4), the reaction mixture was converted to metHb by the addition of small amounts of ferricyanide and maintained at the given temperaturefor 2 days to see if hemichrome precipitation occurred.Thus, the findings suggested that human $\mathrm{HbO}_{2}$ was highly susceptible to hemichrome formation, even under physiological $\mathrm{pH}$ and temperature. The broken lines in Figure $2 \mathrm{a}$ show that the threshold for this susceptibility in relation to $\mathrm{pH}$ and temperature.

On the other hand, Figure $2 b$ manifests that the isolated $a\left(\alpha_{p}\right.$ $\left.{ }_{M B}\right)$ and $\beta\left(\beta_{\mathrm{p}-\mathrm{MB}}\right)$ chains might have much higher susceptibilities to hemichrome formation, when compared with the tetrameric parent molecule, and possess individual susceptibility as detailed in their $\mathrm{pH}-$ temperature diagrams. Isolation of $\alpha$ and $\beta$ chains from the parent molecules was made using sodium $\mathrm{p}$-hydroxymercuribenzoate $(p$ $\mathrm{MB})$ by a one-column method using carboxymethyl (CM)-cellulose and alternatively by a two-column method (the details of which can be referred to in Sugawara et al. [17]).

Hence, the occurrence of hemichrome of human $\mathrm{HbO}_{2}$ can be described as follows:

$$
\mathrm{Hb}(\mathrm{II}) \mathrm{O}_{2} \stackrel{\mathrm{k}_{\mathrm{A}}}{\longrightarrow} \operatorname{metHb}(\mathrm{III})+4\left(\mathrm{O}_{2}{ }^{-{ }^{-}}\right) \rightarrow \text { hemichrome }
$$

Along with this line, the question may be arisen as to whether the monomeric $\mathrm{Mb}\left(\mathrm{MbO}_{2}\right)$ have similar propensity of human $\mathrm{HbO}_{2}$ to hemichrome. Regarding to this issue, a series of experiments using UV/VIS spectroscopic observation for hemichrome emergence (hemichrome emergence tests) were undertaken for monomeric bovine heart $\mathrm{MbO}_{2}$. At first, these tests were conducted in $0.1 \mathrm{M}$ buffer over the same range of $\mathrm{pH}$ ( $\mathrm{pH} 4.5$ to 10.5$)$ and temperature $\left(35\right.$ to $\left.55^{\circ} \mathrm{C}\right)$. However, our attempts failed to recognize any hemichrome emergence in this $\mathrm{pH}$ and temperature range. In order to further check this point, we made an attempt to expand our tests to temperature region exceeding $55^{\circ} \mathrm{C}$. In this respect, we employed thermal denaturation measurement for $\mathrm{MbO}_{2}$ using differential scanning calorimetry (DSC). Ultimately we engaged in these tests over a wide temperature range 
Citation: Sugawara Y, Shigemasa Y, Hayashi Y, Abe Y, Ohgushi I, et al. (2013) New Mode (Molecular-Sensing) of Heinz Body Formation Mechanisms Inherent in Human Erythrocytes: Basis for Understanding of Clinical Aspects of Drug-Induced Hemolytic Anemia and the Like. J Bioanal Biomed 5: 036-056. doi:10.4172/1948-593X.1000078
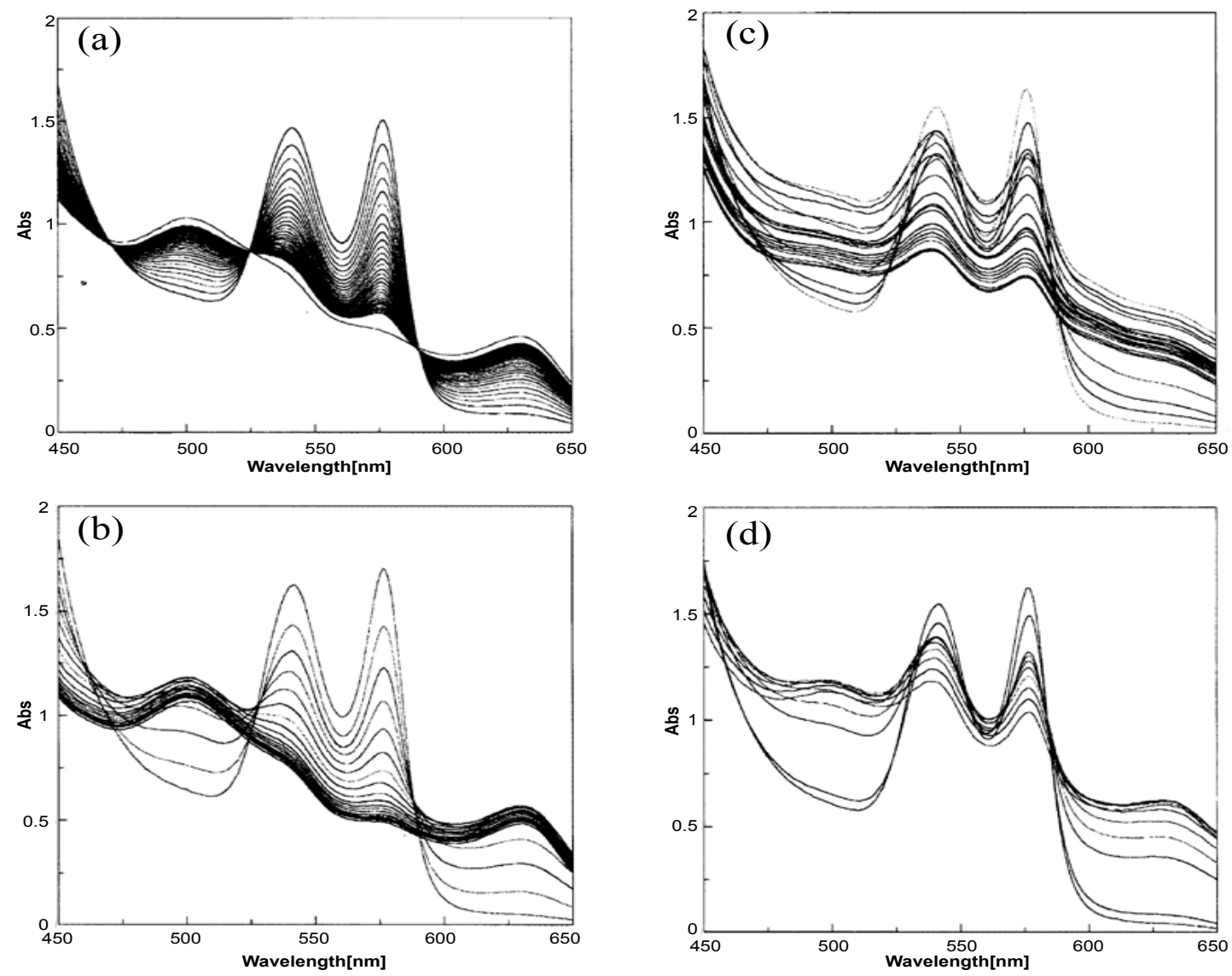

Figure 1: Hemichrome formation associated with human $\mathrm{HbO}_{2}$ autoxidation, redrawn from Sugawara et al. [17]. UV/VIS spectral changes over time for hemichrome formation associated with human $\mathrm{HbO}_{2}$ autoxidation in which the reaction was monitored (a) in $0.1 \mathrm{M} \mathrm{MES} \mathrm{buffer} \mathrm{(} \mathrm{pH} 5.0$ ) at $37^{\circ} \mathrm{C}$ and scanning interval $=15$ min; $(\mathbf{b})$ in $0.1 \mathrm{M}$ MES buffer ( $\mathrm{pH} \mathrm{6.5)}$ ) at $40^{\circ} \mathrm{C}$ and scanning interval $=150 \mathrm{~min}$; (c) in $0.1 \mathrm{M} \mathrm{HEPES}$ buffer $\left(\mathrm{pH} 8.0\right.$ ) at $40^{\circ} \mathrm{C}$ and scanning interval $=150$ min; (d) in $0.1 \mathrm{M} \mathrm{HEPES}$ buffer $(\mathrm{pH} 7.0)$ at $45^{\circ} \mathrm{C}$ and scanning interval $=60$ min. Conditions: $\mathrm{HbO}_{2}$ concentration was $235 \mu \mathrm{M}$ (in heme contents).
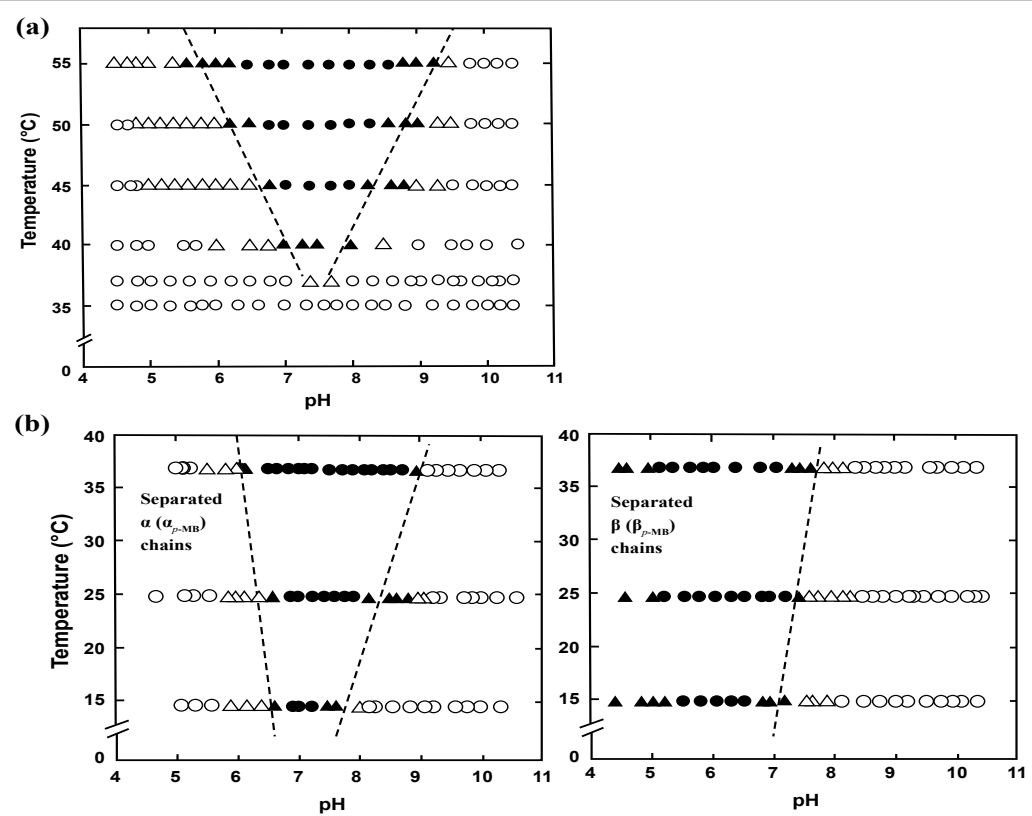

Figure 2: Hemichrome formation associated with human $\mathrm{HbO}_{2}$ autoxidation. (a) $\mathrm{pH}$-temperature diagram for $\mathrm{HbO}_{2}$ autoxidation. (b) $\mathrm{pH}$-temperature diagrams for the autoxidation of isolated $\alpha$ and $\beta$ chains. The symbols used are as follows: - hemichrome formation noticeable at the initial stage during the course of autoxidation; $\Delta$ - at the intermediate stage; $\triangle$ - at the final stage; $\bigcirc$ - autoxidation reaction proceeded with no hemichrome formation during the entire process. 
Citation: Sugawara Y, Shigemasa Y, Hayashi Y, Abe Y, Ohgushi I, et al. (2013) New Mode (Molecular-Sensing) of Heinz Body Formation Mechanisms Inherent in Human Erythrocytes: Basis for Understanding of Clinical Aspects of Drug-Induced Hemolytic Anemia and the Like. J Bioanal Biomed 5: 036-056. doi:10.4172/1948-593X.1000078

for bovine heart $\mathrm{MbO}_{2}$ from physiological to temperatures just before thermal unfolding [17].

Mbs (involving $\mathrm{MbO}_{2}$ and met $\mathrm{Mb}$ ) were isolated from bovine heart muscle, in which the essential step was chromatographic separation of $\mathrm{MbO}_{2}$ from metMb on a DEAE-cellulose column.Thermal denaturation of bovine heart $\mathrm{Mb}$ was assessed by differential scanning calorimetry in terms of $\mathrm{T}_{\mathrm{d}}$, the temperature at which the transition is half complete. A non-adiabatic calorimeter (DSC, Seiko I \&E DSC-10/SSC-570 Thermal Controller Model, Tokyo, Japan) was used at a heating rate of $1^{\circ} \mathrm{C} \cdot \mathrm{min}^{-1}$ and at protein concentrations of $1.5-5.5 \mathrm{mg} \cdot \mathrm{ml}^{-1}$. After treatment of the raw DSC data, in which correction of the sample curve for changes of slope observed in a run with buffer in each cell was made by subtracting the buffer curve from the protein curve point by point, the linear portions of the corrected curve corresponding to pre- and posttransition base lines were extrapolated to $T_{d}$. $T_{d}$ was also determined by successive area measurements until the vertical line drawn at $\mathrm{T}_{\mathrm{d}}$ divided the peak area into two halves. The area under heat capacity curve was determined by means of a planimeter.

Figure $3 \mathrm{a}$ is an example of DSC scanning for $\mathrm{MbO}_{2}$ in $0.1 \mathrm{M}$ HEPES buffer at $\mathrm{pH}$ 7.4. In terms of $\mathrm{T}_{\mathrm{d}}$, that is, the temperature at which the thermal unfolding is half complete, Figure $3 \mathrm{~b}$ gives an upper limit temperature to examine whether hemichrome formation associated with autoxidation can be observed in monomeric $\mathrm{MbO}_{2}$ or not, although the concentration $(0.91 \mathrm{mM})$ used for DSC measurement was 100 times higher than that of our hemichrome emergence test.

Considering an upper limit temperature in each run, our search for detecting possible hemichrome emergence was carried out by varying $\mathrm{pH}$ of the solution from 4.5 to 10.5 and varying the temperature from the physiological level to the level just before thermal unfolding. Typical examples are shown in Figure $3 \mathrm{c}$ and $3 \mathrm{~d}$, where $\mathrm{k}_{\mathrm{A}}$ represents the observed first-order rate constant of autoxidation of $\mathrm{MbO}_{2}$ at a given $\mathrm{pH}$ and temperature. In air-saturated buffers, $\mathrm{MbO}_{2}$ is oxidized by the bound $\mathrm{O}_{2}$ to its ferric met form (metMb) with generation of superoxide anion radical $\left(\mathrm{O}_{2}^{-}\right)$as essentially in the same manner as $\mathrm{HbO}_{2}$ :

$$
\mathrm{Mb}(\mathrm{II}) \mathrm{O}_{2} \stackrel{\mathrm{k}_{\mathrm{A}}}{\longrightarrow} \operatorname{metMb}(\mathrm{III})+\mathrm{O}_{2}
$$

Here $\mathrm{k}_{\mathrm{A}}$ is given by:

$$
\mathrm{d}\left[\mathrm{MbO}_{2}\right] / \mathrm{dt}=\mathrm{k}_{\mathrm{A}} \cdot\left[\mathrm{MbO}_{2}\right]
$$

In the hemichrome emergence tests, the ratio of $\mathrm{MbO}_{2}$ concentration after time $t$ to that at time $t=0$ was monitored by absorbance change, for instance, at $\alpha$-peak (581 nm) of $\mathrm{MbO}_{2}$. In each run, $\mathrm{k}_{\mathrm{A}}$ in $\mathrm{hr}^{-1}$ was determined from the slope of linear plots of $-\ln \left(\left[\mathrm{MbO}_{2}\right]_{t} /\left[\mathrm{MbO}_{2}\right]_{0}\right)$ versus time and plotted against temperature of the solution in Figure $3 \mathrm{c}$ and against the inverse of the absolute temperature, that is Arrhenius plots in Figure 3d. In these figures, our experimental data gave a single straight line against the temperature examined at constant $\mathrm{pH}$ of the solution.This implies that there was no hemichrome emergence (formation) under these circumstances. This point was also confirmed by the resulting activation energy, $E_{\mathrm{A}}$. From the slope of each straight line on Arrhenius plots shown in Figure $3 \mathrm{~d}, E_{\mathrm{A}}$ was calculated and appeared to be almost constant, i.e., $121.55 \pm 14.38 \mathrm{KJ} \cdot \mathrm{mol}^{-1}(29.08 \pm$ $3.44 \mathrm{Kcal} \cdot \mathrm{mol}^{-1}$ ) over the $\mathrm{pH}$ range of 4.5 to 10.5 and at the temperature range greater than or equal to $35^{\circ} \mathrm{C}$. These were in good agreement with those observed by Goto and Shikama [36], where $\mathrm{E}_{\mathrm{A}}$ is almost constant with the value of $26.5 \mathrm{Kcal} \cdot \mathrm{mol}^{-1}\left(110.77 \mathrm{KJ} \cdot \mathrm{mol}^{-1}\right)$ over $\mathrm{pH}$ range of 5 to 10 using bovine heart $\mathrm{MbO}_{2}$ based on the measurements of the rate at $0,15,25$, and $30^{\circ} \mathrm{C}$.

$\mathrm{We}$, therefore, concluded that the monomeric bovine heart $\mathrm{Mb}$ $\left(\mathrm{MbO}_{2}\right)$ did not show any propensity for hemichrome formation over a wide $\mathrm{pH}$ range of 4.5 to 10.5 and over a wide temperature range (a)

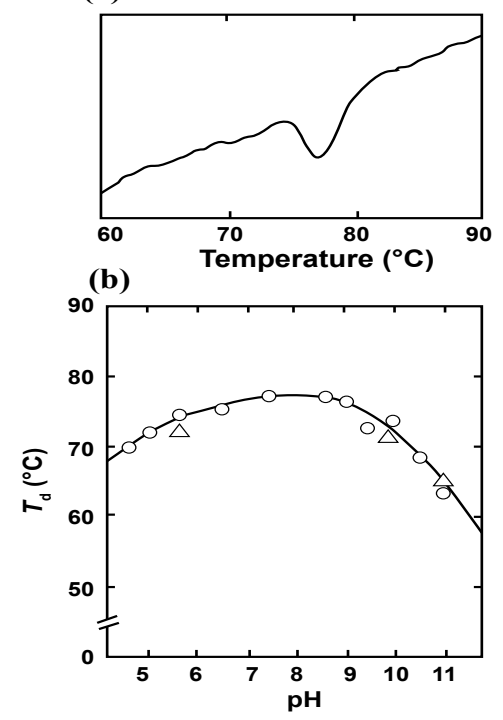

(c)

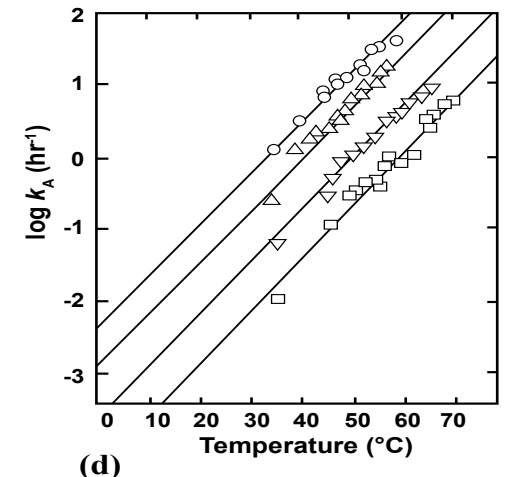

(d)

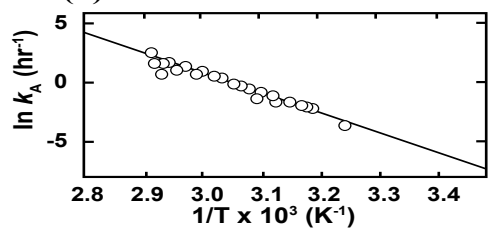

Figure 3: Hemichrome formation test for monomeric bovine heart $\mathrm{Mb}$. (a) Tracing of DSC curve for unfolding of bovine heart $\mathrm{MbO}_{2}$ in $0.1 \mathrm{M} \mathrm{HEPES}$ buffer at $\mathrm{pH} 7.4$. Protein concentration was $2.35 \mathrm{mg} \cdot \mathrm{ml}^{-1}(0.91 \mathrm{mM})$. (b) By means of DSC, the properties of thermal unfolding of bovine heart $\mathrm{MbO}_{2}$ and metMb were depicted as a function of $\mathrm{pH}$ and temperature in terms of $T_{\mathrm{d}}$ (i.e., the temperature at which the transition is half complete). Protein concentration was $1.5-5.5 \mathrm{mg}^{-1}$ ( 0.91 to 5.81 $\mathrm{mM}$ ). $\circ: \mathrm{MbO}_{2}, \Delta:$ metMb. (c) Temperature dependence of first-order rate constants, $k_{\mathrm{A}}$ of autoxidation of bovine heart $\mathrm{MbO}_{2}$. The autoxidation was measured in 0.1 $\mathrm{M}$ buffer at a given $\mathrm{pH}$ and temperature under air saturated condition. The resulting data of $\mathrm{pH} 5.0$ in $0.1 \mathrm{M} \mathrm{MES}$ buffer (o), 6.0 in $0.1 \mathrm{M}$ MES buffer ( $\Delta$ ), 7.0 in $0.1 \mathrm{M}$ HEPES buffer $(\nabla)$ and 9.0 in $0.1 \mathrm{M} \mathrm{CHES}$ buffer $(\square)$ were plotted against a given temperature. $\mathrm{MbO}_{2}$ concentration was $97 \mu \mathrm{M}$. (d) Arrhenius plot of $k_{\mathrm{A}}$, measured in $0.1 \mathrm{M}$ HEPES buffer at $\mathrm{pH} 7.4$. 
Citation: Sugawara Y, Shigemasa Y, Hayashi Y, Abe Y, Ohgushi I, et al. (2013) New Mode (Molecular-Sensing) of Heinz Body Formation Mechanisms Inherent in Human Erythrocytes: Basis for Understanding of Clinical Aspects of Drug-Induced Hemolytic Anemia and the Like. J Bioanal Biomed 5: 036-056. doi:10.4172/1948-593X.1000078

from physiological to temperatures just before thermal unfolding. Contradictorily, higher susceptibilities to hemichrome formation as well as occurrence of hemichrome emergence even under physiological $\mathrm{pH}$ and temperature was pronounced to be the most significant feature of the tetrameric human $\mathrm{HbO}_{2}$ that is $\mathrm{O}_{2}$-carrying protein in the blood.

\section{Oxidative behavior of human $\mathrm{Hb}\left(\mathrm{HbO}_{2}\right)$ : $\mathrm{pH}-$ Dependent biphasic autoxidation curves seen in acidic solutions}

Since the early works of Brooks [37,38], the oxidative process (autoxidation) of human $\mathrm{Hb}$ has been investigated by several researchers. Among others, Monsouri and Winterhalter [39] and Tomoda et al. [40] observed that the rate of autoxidation was strongly dependent upon the $\mathrm{pH}$ values of solutions. The study of Monsouri and Winterhalter [39] also showed that autoxidation of human $\mathrm{HbO}_{2}$ exhibited a biphasic nature, with an initial fast $\left(\mathrm{k}_{\mathrm{A}}{ }^{\mathrm{f}}\right)$ reaction followed by a second slower $\left(\mathrm{k}_{\mathrm{A}}^{\mathrm{s}}\right)$ reaction, when observed in acidic solutions. Following the method of Monsouri and Winterhalter [39], we here focus on the biphasic nature of the autoxidation seen in acidic solutions on the basis of our previous report [35].

As previously shown, Figure $1 \mathrm{a}$ is a representative example, in which $\mathrm{HbO}_{2}$ was autoxidized to its ferric met form through the tendency of the bound $\mathrm{O}_{2}$ to oxidize ferrous heme iron (II) with generation of superoxide anionradical $\left(\mathrm{O}_{2}^{-}\right)$, as in the same fashion in $\mathrm{MbO}_{2}$ autoxidation mentioned above:

$$
\mathrm{Hb}(\mathrm{II}) \mathrm{O}_{2} \stackrel{\mathrm{k}_{\mathrm{A}}}{\longrightarrow} \operatorname{metHb}(\mathrm{III})+4\left(\mathrm{O}_{2}^{-{ }^{-}}\right)
$$

Here $\mathrm{k}_{\mathrm{A}}$ represents the observed rate constant of the reaction at a given $\mathrm{pH}$ and temperature. The reaction process was followed in each experimental run by the ratio $\left(\left[\mathrm{HbO}_{2}\right]_{\mathrm{t}} /\left[\mathrm{HbO}_{2}\right]_{0}\right)$ of $\mathrm{HbO}_{2}$ concentration after time $t$ to that at time $\mathrm{t}=0$ that was monitored by the absorbance ratio of $\left(\mathrm{A}_{t}-\mathrm{A}_{\infty}\right) /\left(\mathrm{A}_{0}-\mathrm{A}_{\infty}\right)$ at $576 \mathrm{~nm}\left(\alpha\right.$-peak of $\left.\mathrm{HbO}_{2}\right)$. The ratio was then plotted against time. Each curve shown in Figure $4 \mathrm{a}$ represents the $-\ln \left(\left[\mathrm{HbO}_{2}\right]_{t} /\left[\mathrm{HbO}_{2}\right]_{0}\right)$ versus time plot (first-order plot) for this phenomenon. In acidic-to-neutral solutions, the reaction was biphasic and can be described by first-order kinetics containing two rate constants as follows:

$$
\mathrm{d}\left[\mathrm{HbO}_{2}\right] / \mathrm{dt}=\mathrm{P} \cdot \exp \left(-\mathrm{k}_{\mathrm{A}}{ }^{\mathrm{f}} \cdot \mathrm{t}\right)+(1-\mathrm{P}) \cdot \exp \left(-\mathrm{k}_{\mathrm{A}}^{\mathrm{s}} \cdot \mathrm{t}\right)
$$

This equation was originally proposed by Monsouri and Winterhalter [39], where $\mathrm{k}_{\mathrm{A}}{ }_{\mathrm{f}}$ and $\mathrm{k}_{\mathrm{A}}{ }^{\mathrm{s}}$ represent first-order rate constants for the initial fast oxidation and the second slower oxidation, respectively, and $P$ is the molar fraction of the initial fast component. In the Figure, solid lines represent the best fitting derived by the leastsquares method using the equation to each run. However, when the $\mathrm{pH}$ of solutions is more than 8 , a plot of $-\ln \left(\left[\mathrm{HbO}_{2}\right]_{t} /\left[\mathrm{HbO}_{2}\right]_{0}\right)$ versus time showed a single-phase reaction with a single first-order rate constant, although curve fittings could be made using the same equation under conditions setting $\mathrm{P}=0.5$ and $\mathrm{k}_{\mathrm{A}}{ }^{\mathrm{f}}=\mathrm{k}_{\mathrm{A}}{ }_{\mathrm{A}}^{\text {s }}$. Thus, it was shown that the biphasic behavior seen in acidic solutions gradually disappeared with increasing $\mathrm{pH}$ of solutions and completely disappeared if the $\mathrm{pH}$ of solutions was more than 8 .

In this way, the kinetic parameters and molar fraction of the initial fast component $(\mathrm{P})$ for the biphasic nature of human $\mathrm{HbO}_{2}$ autoxidation were established in each run in $0.1 \mathrm{M}$ buffer at $37^{\circ} \mathrm{C}$ (Table 1). It was evident that the values of $P$ varied from 0.47 to 0.53 . This means that $\mathrm{HbO}_{2}$ was autoxidized with half of the component

\begin{tabular}{|c|c|c|c|c|}
\hline $\mathrm{pH}$ & $P$ & $\begin{array}{c}\boldsymbol{k}_{\mathrm{A}}^{f} \\
\left(\mathbf{h}^{-1}\right)\end{array}$ & $\begin{array}{c}\boldsymbol{k}_{\mathbf{A}}^{\mathbf{s}} \\
\left(\mathbf{h}^{-1}\right)\end{array}$ & $k_{\mathrm{A}}^{s} / k_{\mathrm{A}}^{f}$ \\
\hline 5.3 & 0.47 & 0.438 & 0.078 & 0.178 \\
\hline 5.9 & 0.48 & 0.270 & 0.030 & 0.111 \\
\hline 6.2 & 0.48 & 0.134 & 0.0154 & 0.115 \\
\hline 6.55 & 0.49 & 0.070 & 0.010 & 0.142 \\
\hline 6.9 & 0.53 & 0.0465 & 0.0073 & 0.157 \\
\hline 9.15 & 0.50 & 0.0095 & 0.0095 & 1.0 \\
\hline 9.5 & 0.50 & 0.0184 & 0.0184 & 1.0 \\
\hline 9.7 & 0.50 & 0.0381 & 0.0381 & 1.0 \\
\hline 10.2 & 0.50 & 0.080 & 0.080 & 1.0 \\
\hline 10.4 & 0.50 & 0.157 & 0.157 & 1.0 \\
\hline
\end{tabular}
via the reaction process with the initial fast reaction with $\mathrm{k}_{\mathrm{A}}{ }_{\mathrm{f}}$ and the
Table 1: Summary of kinetic parameters for the autoxidation of human $\mathrm{HbO}_{2}$ in $0.1 \mathrm{M}$ buffer obtained by least-squares fitting to the experimental data in each run, redrawn from Sugawara et al. [34]

other half via the procedure with the second slower rate $\left(\mathrm{k}_{\mathrm{A}}^{\mathrm{s}}\right)$. Thus, autoxidation of human $\mathrm{HbO}_{2}$ may be written as follows:

$$
\begin{gathered}
\mathrm{Hb}(\mathrm{II}) \mathrm{O}_{2} \frac{\mathrm{k}_{\mathrm{A}}{ }^{\mathrm{f}}}{\mathrm{k}_{\mathrm{a}}{ }^{\mathrm{s}}} \\
\longrightarrow 1 / 2 \operatorname{metHb}(\mathrm{III})+4\left(\mathrm{O}_{2}{ }^{-}\right) \\
\longrightarrow 1 / 2 \operatorname{metHb}(\mathrm{III})
\end{gathered}
$$

To clarify the processes behind this phenomenon, the obtained values of $\mathrm{k}_{\mathrm{A}}{ }^{s} / \mathrm{k}_{\mathrm{A}}{ }_{\mathrm{f}}$ were plotted against the $\mathrm{pH}$ of solutions (Figure $4 \mathrm{~b}$ ). In the Figure, the solid line shows that the computed curve obtained by the least-squares method fitted the experimental data over the whole range of $\mathrm{pH}$ 5-10.5, where a single dissociable group, $\mathrm{AH}$ with $\mathrm{K}_{\mathrm{a}}$, was assumed to be involved in the reaction:

$$
\mathrm{HbO}_{2}(\mathrm{AH}) \stackrel{K_{a}}{\longleftrightarrow} \mathrm{HbO}_{2}\left(\mathrm{~A}^{-}\right)
$$

For neutral amino acids, acid-base equilibrium is usually given by the dissociation constant: $\mathrm{AH} \leftrightarrow \mathrm{A}^{-}+\mathrm{H}^{+}$and thus $\mathrm{K}_{\mathrm{a}}=\left[\mathrm{A}^{-}\right] \cdot\left[\mathrm{H}^{+}\right] /[\mathrm{AH}]$. The best fitting was achieved when $\mathrm{pK}_{\mathrm{a}}=7.4$ (at $37^{\circ} \mathrm{C}$ ). In this regard, Hermans and Rialdi [41,42] reported microcalorimetric ionization data on amino-acid residues for sperm whale myoglobin $(\mathrm{Mb})$ in which they assigned the His residue with values of $\mathrm{pK}_{\mathrm{a}}=6.62$, the standard Gibbs energy $\left(\Delta \mathrm{G}^{\circ}\right)=37.7 \mathrm{~kJ} \cdot \mathrm{mol}^{-1}$, the enthalpy $(\Delta \mathrm{H})=29.7 \mathrm{~kJ} \cdot \mathrm{mol}^{-1}$, and the entropy $\left(\Delta S^{\circ}\right)=-26.8 \mathrm{~J} \cdot \mathrm{mol}^{-1} \cdot \mathrm{K}^{-1}$. It is unwise to identify a dissociation group only by its $\mathrm{pK}_{\mathrm{a}}$ value because of the anomalies often found in proteins. Hence, we confirmed that AH must be a His residue assuming that the primary and tertiary structures of $\alpha$ and $\beta$ subunits are remarkably similar to each other and to $\mathrm{Mb}$. This fact provides information for the existence of a $\mathrm{pH}$-sensed molecular device that can manifest the biphasic autoxidation of the $\mathrm{HbO}_{2}$ tetramer via participation of a single amino-acid residue with $\mathrm{pK}_{\mathrm{a}}=7.4\left(\right.$ at $37^{\circ} \mathrm{C}$ ).

In order to not only elucidate the biphasic characteristics of human $\mathrm{HbO}_{2}$ autoxidation but also to clarify how the $\mathrm{Hb}$ molecule can prompt the range of fast $\left(\mathrm{k}_{\mathrm{A}}{ }^{\mathrm{f}}\right)$ and slow $\left(\mathrm{k}_{\mathrm{A}}^{\mathrm{s}}\right)$ components against $\mathrm{pH}$ values of the solutions, chain separation of the constituted chains from the parent molecules and rate measurements for the separated chains were conducted. Chain separation was made using p-MB [17], as mentioned above.

Figure 5 shows the obtained $\mathrm{pH}$ profiles for the autoxidation rate of the isolated $\alpha_{\mathrm{p}-\mathrm{MB}}$ and $\beta_{\mathrm{p}-\mathrm{MB}}$ chains. With reference to the rates $\left(\mathrm{k}_{\mathrm{A}}{ }^{\mathrm{f}}\right.$ and $\mathrm{k}_{\mathrm{A}}{ }^{\mathrm{s}}$ ) of the parent molecules calculated from biphasic autoxidation curves, the isolated chains were shown to be oxidized much more 
Citation: Sugawara Y, Shigemasa Y, Hayashi Y, Abe Y, Ohgushi I, et al. (2013) New Mode (Molecular-Sensing) of Heinz Body Formation Mechanisms Inherent in Human Erythrocytes: Basis for Understanding of Clinical Aspects of Drug-Induced Hemolytic Anemia and the Like. J Bioanal Biomed 5: 036-056. doi:10.4172/1948-593X.1000078
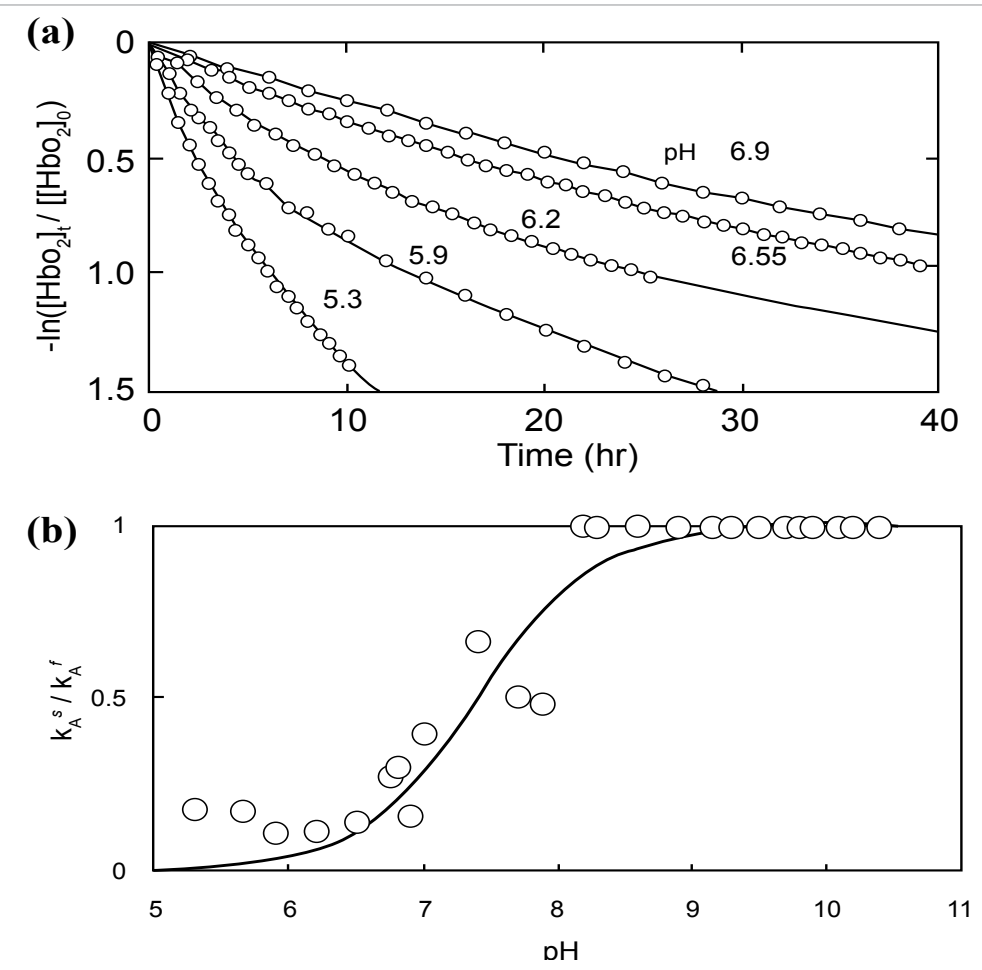

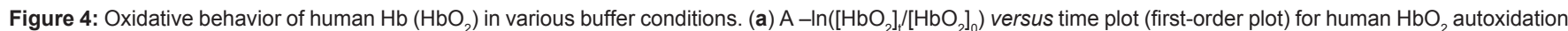
Two-phase autoxidation with an initial fast reaction $\left(k_{A}^{f}\right)$ followed by a second slower reaction $\left(k_{A}^{s}\right)$ seen in acidic-to-neutral pH ranges. Solid lines represent the leastsquares fitting to experimental data in each run. Conditions: $\mathrm{HbO}_{2}$ concentration was $50-125 \mu \mathrm{M}$ (in heme contents); and the reaction proceeded in $0.1 \mathrm{M}$ buffer at $37^{\circ} \mathrm{C}$. (b) A $k_{A}^{s} / k_{A}^{f}$ versus $\mathrm{pH}$ plot for human $\mathrm{HbO}_{2}$ autoxidation. The solid line stands for the best-suited fitting under the assumption that a single, dissociable group, $\mathrm{AH}$ with $K_{a}$, can be involved in the reaction. This was achieved with the setting $p K_{a}=7.4$.

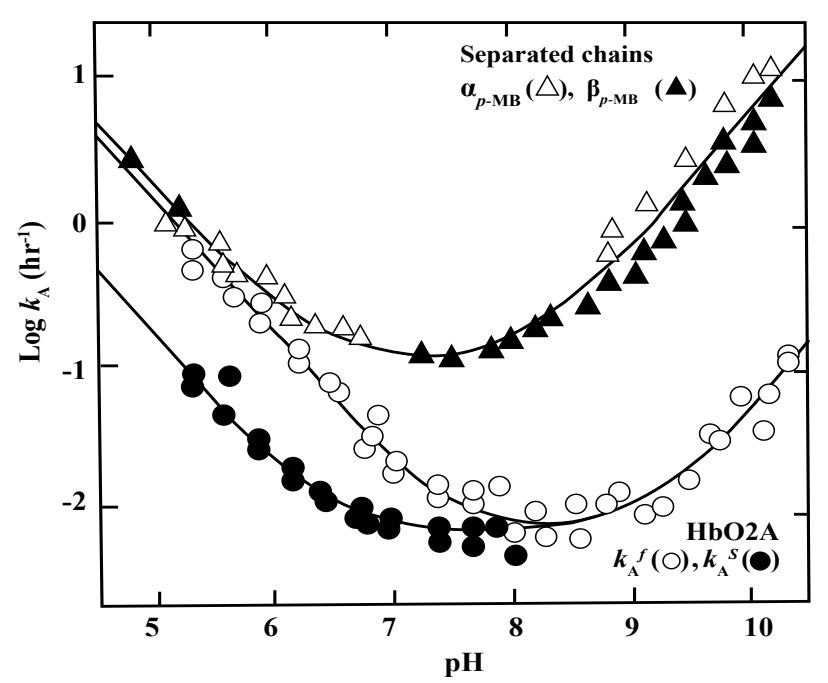

Figure 5: Logarithmic values of first-order rate versus $\mathrm{pH}$ plot for autoxidation of the isolated $\alpha\left(\alpha_{p-\mathrm{MB}}\right)$ and $\beta\left(\beta_{p-\mathrm{MB}}\right)$ chains with a reference to the relevant values $\left(k_{A}{ }^{f}\right.$ and $k_{\mathrm{A}}^{s}$ ) of the parent molecules, redrawn from Sugawara et al. [34]. Conditions: the concentration of isolated $\alpha$ and $\beta$ chains was $50 \mu \mathrm{M}$ (in heme contents); the reaction rate was measured in $0.1 \mathrm{M}$ buffer at $37^{\circ} \mathrm{C}$.

rapidly to the ferric met-form over the entire $\mathrm{pH}$ range (5-10.5) because the reaction followed simple, first-order kinetics as follows:

$$
\mathrm{Hb}_{\text {sub }}(\mathrm{II}) \mathrm{O}_{2} \stackrel{\mathrm{k}_{\mathrm{A}}^{\text {sub }}}{\longrightarrow} \text { metHb } \mathrm{sub}(\mathrm{III})+4\left(\mathrm{O}_{2}{ }^{--}\right)
$$

Where $\mathrm{Hb}_{\text {sub }}$ represents each subunit of the $\mathrm{Hb}$ molecule. It was also shown that the rate of the initial first component $\left(\mathrm{k}_{\mathrm{A}}{ }^{\mathrm{f}}\right)$ of the parent molecules was found to lie closer to the values of $\mathrm{k}_{\mathrm{A}}$ for the isolated $\alpha_{\mathrm{p}-\mathrm{MB}}$ and $\beta_{\mathrm{p}-\mathrm{MB}}$ chains if the $\mathrm{pH}$ of solutions was less than 6. Similar $\mathrm{pH}$ profiles were obtained for $p$-MB-removed chains, i.e., the $\alpha_{\mathrm{SH}}$ and $\beta_{\mathrm{SH}}$ chains. $p-\mathrm{MB}$ can be removed from the $\alpha_{\mathrm{p}-\mathrm{MB}}$ and $\beta_{\mathrm{p}-\mathrm{MB}}$ chains by incubation with 2-mercaptoethanol, as described elsewhere [30]. In separated-chain solutions, the protein is known to exist in equilibrium 
Citation: Sugawara Y, Shigemasa Y, Hayashi Y, Abe Y, Ohgushi I, et al. (2013) New Mode (Molecular-Sensing) of Heinz Body Formation Mechanisms Inherent in Human Erythrocytes: Basis for Understanding of Clinical Aspects of Drug-Induced Hemolytic Anemia and the Like. J Bioanal Biomed 5: 036-056. doi:10.4172/1948-593X.1000078

of $\alpha \leftrightarrow \alpha_{2}$ or $\beta \leftrightarrow \beta_{4}$, respectively. Under our experimental conditions, the monomeric form (87\%) was present in the separated $\alpha$ chain, whereas the tetrameric form (99\%) was predominant in the $\beta$ chain. This estimation was made on the basis of the results by McDonald et al. [16]. Accordingly it became evident that the isolated $\alpha$ and $\beta$ chains could be oxidized much more readily over the measured $\mathrm{pH}$ range (510.5) when compared with the respective rates of the parent molecules as a reference. With respect to the difference in the rate between the isolated individual chains, this seemed to be within reasonable experimental errors in the values of $\alpha_{\mathrm{p}-\mathrm{MB}}$ and $\beta_{\mathrm{p}-\mathrm{MB}}$ chains, and the $\alpha_{\mathrm{SH}}$ and $\beta_{\mathrm{SH}}$ chains.

Thus, the obtained findings put forward an idea that the individual chains have acquired considerable resistance to oxyheme autoxidation in their tetrameric protein architecture. The same appears to be the case in which human $\mathrm{HbO}_{2}$ has acquired a $\mathrm{pH}$-sensitive molecular device, whereby participation of a single dissociation group of amino-acid residue (probably a His residue) with $\mathrm{pK}_{\mathrm{a}}=7.4\left(\right.$ at $37^{\circ} \mathrm{C}$ ) plays a key role, as a consequence of development of the tetrameric protein architecture. We will see later that this issue was the starting point that led us to uncover a new mode of subunit interaction of the $\mathrm{Hb}$ molecule that can be emerged from participation of the $\alpha_{1}-\beta_{1}$ (and $\alpha_{2}-\beta_{2}$ ) interface via distal side perturbations within the heme pocket relying upon inherent tilting capability of the distal (E7) His residues (i.e., a58His (E7) in the $\alpha$ chain and $\beta 63$ His (E7) in the $\beta$ chain).

We must be careful when evaluating the data of the isolated chains shown in Figure 5. Because of the instability of $\mathrm{Hb}$ molecules and their relationship to hemichrome, the first-order rate constant for the isolated chains was established in each experimental run using only the initial slope of the $-\ln \left(\left[\mathrm{Hb}_{\text {sub }} \mathrm{O}_{2}\right]_{t} /\left[\mathrm{Hb}_{\text {sub }} \mathrm{O}_{2}\right]_{0}\right)$ versus time plot. Once hemichrome precipitation arose, one could not get the endpoint spectrum (the ferric met form) of the reaction, whereby $\mathrm{Hb}$ molecules in the reaction mixture should be all completely converted to the ferric met form by addition of potassium ferricyanide. Hence, measurement must be confined within the initial range, in which existence of isosbestic points of the spectra that means non-occurrence of hemichrome formation during the entire reaction process was surely guaranteed.

\section{Hemichrome emergence and subsequent formation of heinz bodies within erythrocytes: observation in normal human erythrocytes during mild heating}

Herein we consider the results of our study investigating the formation of Heinz bodies in normal human erythrocytes [32-34]. Aliquots of freshly drawn venous blood from healthy donors were subjected to mild heating at desired temperature above $37^{\circ} \mathrm{C}$ for 30 min to investigate hemichrome formation and subsequent Heinzbody formation in normal human erythrocytes. Heinz bodies were then visualized by exposing blood smears to acetylphenylhydrazine and staining with crystal violet. Changes within the erythrocytes were observed using light microscopy under oil immersion.

Prior to the acetylphenylhydrazine test $[42,43]$, blood samples were subjected to mild heating in vitro. A 2-mL sample was placed in a test tube and incubated in a water bath maintained at each desired temperature $\left( \pm 0.1^{\circ} \mathrm{C}\right)$ above $37^{\circ} \mathrm{C}$ for 30 min using a NESLAB temperature control system (Model RTE-100 or 111 or 210 or 221). In each experimental run, we employed a temperature-untreated reference as a control. The blood sample used as a temperature- untreated reference was kept at a low temperature $\left(0-4^{\circ} \mathrm{C}\right)$ for as long as possible after withdrawal from the donor, and never exposed to temperatures above room temperature.

$\beta$-Acetylphenylhydrazine and crystal violet (research grade for pathology) were used (Wako Pure Chemical, Co., Osaka, Japan) for the procedure, as described by Bauer [43]. A 0.1-mL aliquot of blood sample was suspended in $2 \mathrm{~mL}$ of acetylphenylhydrazine solution, in which $100 \mathrm{mg}$ of acetylphenylhydrazine and $200 \mathrm{mg}$ of glucose in 100 $\mathrm{mL}$ of $0.067 \mathrm{M}$ phosphate buffer were dissolved at $\mathrm{pH}$ 7.6. Using a "blowout" pipette, the solution was aerated twice or thrice by drawing it up into the pipette and blowing it out, together with a small quantity of air. This mixture was incubated at $37^{\circ} \mathrm{C}$ for $2 \mathrm{~h}$. Aeration was repeated halfway through and immediately after the 2-h incubation. A drop (approximately $10 \mu \mathrm{L}$ ) of the resulting mixture was placed on a coverslip, which was then inverted onto a microscope slide containing $30 \mu \mathrm{L}$ of crystal violet solution. The smear was allowed to stand for $20 \mathrm{~min}$ in wet preparation at room temperature and subsequently examined under a light microscope (Nikon Model-FXA; Nikon Co., Tokyo, Japan) equipped with a digital camera (Olympus Model-DP-70; Olympus Co., Tokyo, Japan). Photomicrographs were taken under oil immersion at 1,000× magnification. Subsequently, the number of Heinz bodies per cell was counted in 100 red cells per view.

Figure 6 shows representative images of Heinz bodies within normal red corpuscles (obtained from a healthy donor) during mild heating to a given temperature with using a temperature-untreated reference as a control. Heinz bodies were observed in each smear. Figure 7 puts on view about an entire image of changes of the number of the Heinz bodies per cell in each smear. Here histograms of samples treated at $37^{\circ} \mathrm{C}, 40^{\circ} \mathrm{C}, 42^{\circ} \mathrm{C}$ and $45^{\circ} \mathrm{C}$ are displayed with a temperatureuntreated sample as a reference based on the number of Heinz bodies contained in each of 100 red cells per view. These results confirmed that Heinz-body formation increased with increasing temperature of blood samples treated at temperatures more than $37^{\circ} \mathrm{C}$. Red cells in blood samples exposed to $48^{\circ} \mathrm{C}$ were hemolyzed. Some of the changes are also shown in Figure 8a; histograms of the samples treated at $37^{\circ} \mathrm{C}$ and $42^{\circ} \mathrm{C}$ are laid out with a temperature-untreated sample as a reference.

The other histograms shown in Figure 8b-8f represent the results from another five healthy donors, with a temperature-untreated sample as a reference. Although there was considerable inter-individual variation, temperature-dependent Heinz-body formation was apparent in all preparations. Arithmetic summation was used for all histograms to reduce variability and allow better assessment of temperaturedependent Heinz-body formation. The results of this summation are shown in Figure 9. Solid lines represent the curves derived using the least-squares method using a Gaussian curve. Each computed curve showed satisfactory-to-good agreement with the experimental data over the entire range. The following is a summary of the Gaussian constants resulting from the least-squares fitting: a (peak height $)=101$, $\mathrm{b}$ (peak width at half of maximum $)=5.0$ and $\mathrm{c}$ (peak location $)=4.0$ for blood samples treated at $42^{\circ} \mathrm{C} ; \mathrm{a}=215, \mathrm{~b}=3.5$ and $\mathrm{c}=1.0$ for blood samples treated at $37^{\circ} \mathrm{C}$; and $\mathrm{a}=215, \mathrm{~b}=3.0$ and $\mathrm{c}=0.8$ for temperatureuntreated blood samples.

In vitro evaluation of blood fluidity during mild heating using a micro-channel array flow analyzer (MC-FAN) to provide an index of erythrocyte deformability

In 1992, Kikuchi et al. (1992) described a tool for measuring 


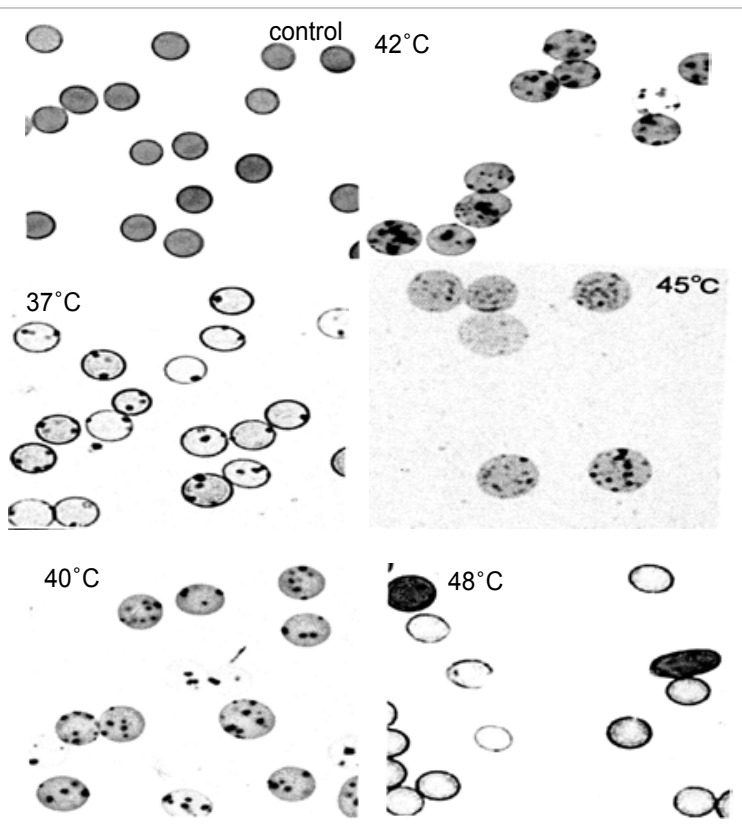

Figure 6: Microscopic views of Heinz bodies after mild heating of blood samples obtained from one healthy donor, redrawn from Sugawara et al. [32]. Using a temperature-untreated sample as a control, aliquots of freshly drawn venous blood were subjected to mild heating at $37^{\circ} \mathrm{C}, 40^{\circ} \mathrm{C}, 42^{\circ} \mathrm{C}, 45^{\circ} \mathrm{C}$ and $48^{\circ} \mathrm{C}$ for 30 min Heinz bodies were then visualized by exposure to acetylphenylhydrazine and dyeing with crystal violet. The changes that occurred within erythrocytes were observed by light microscopy under oil immersion.

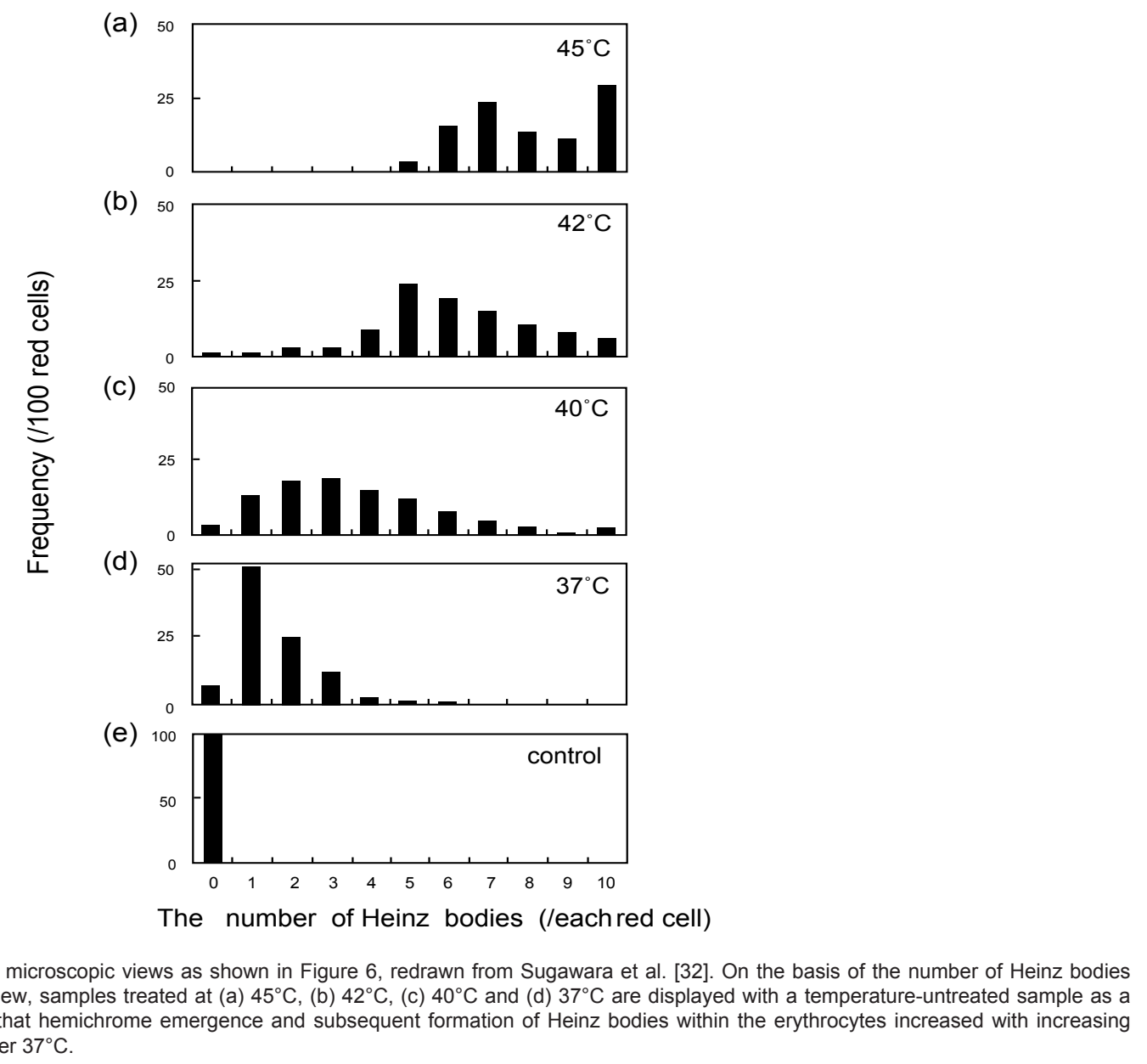
reference (e). The results demonstrate that hemichrome emergence and subsequent formation of Heinz bodies within the erythrocytes increased with increasing temperature treated of blood samples over $37^{\circ} \mathrm{C}$. 

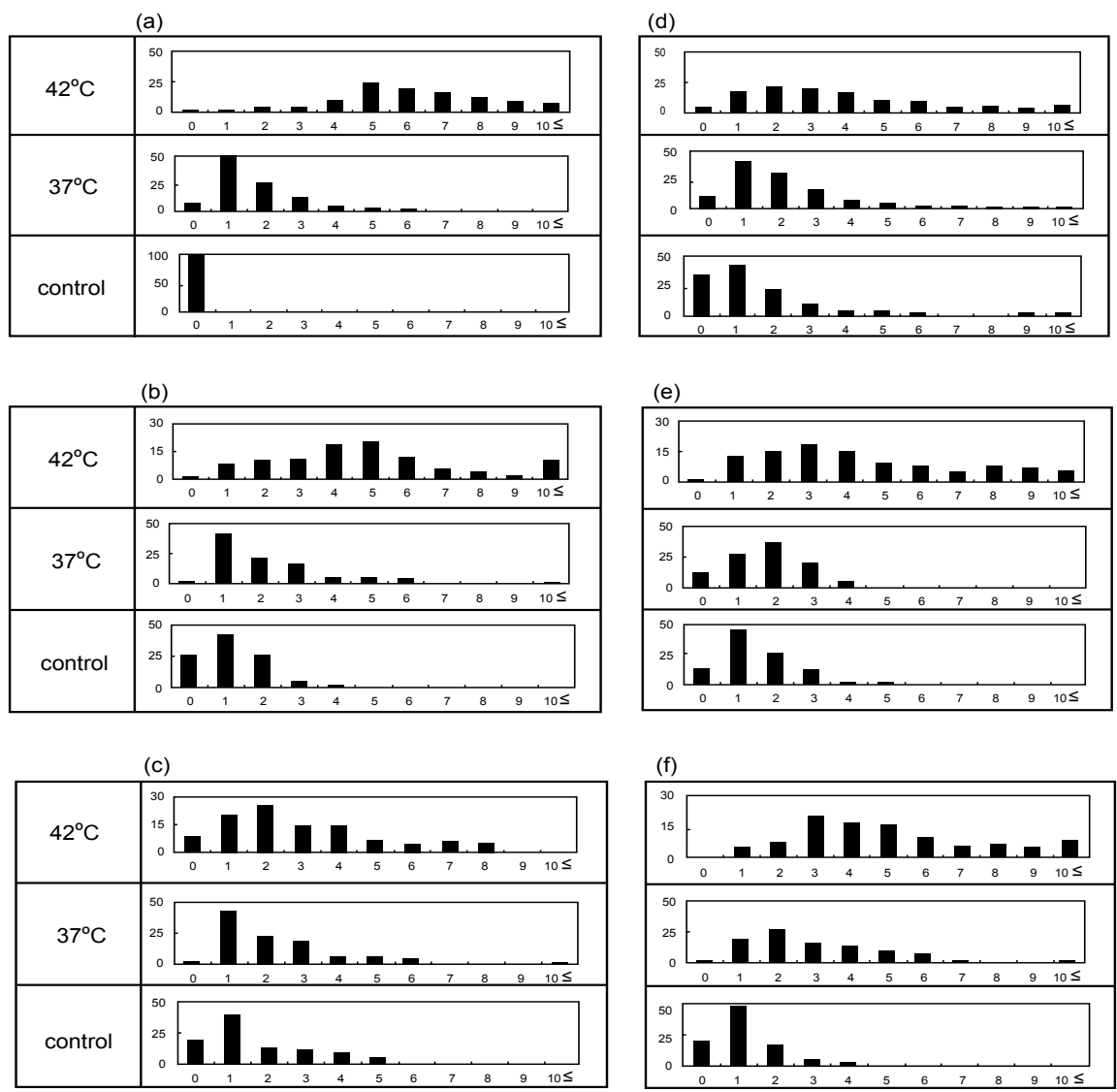

Figure 8: Histograms representing Heinz bodies detected in blood samples after mild heating at $>37^{\circ} \mathrm{C}$, redrawn from Sugawara et al. [32]. The histograms for $37^{\circ} \mathrm{C}$ and $42^{\circ} \mathrm{C}$ are displayed using a temperature-untreated sample as a reference. One-hundred red cells were chosen, and the number of Heinz bodies contained in each red cell counted. (a) was constructed from the microscopic views (Figure 6) and the concerned histograms shown in Figure 7 , whereas (b-f) represent the results from another five healthy donors.

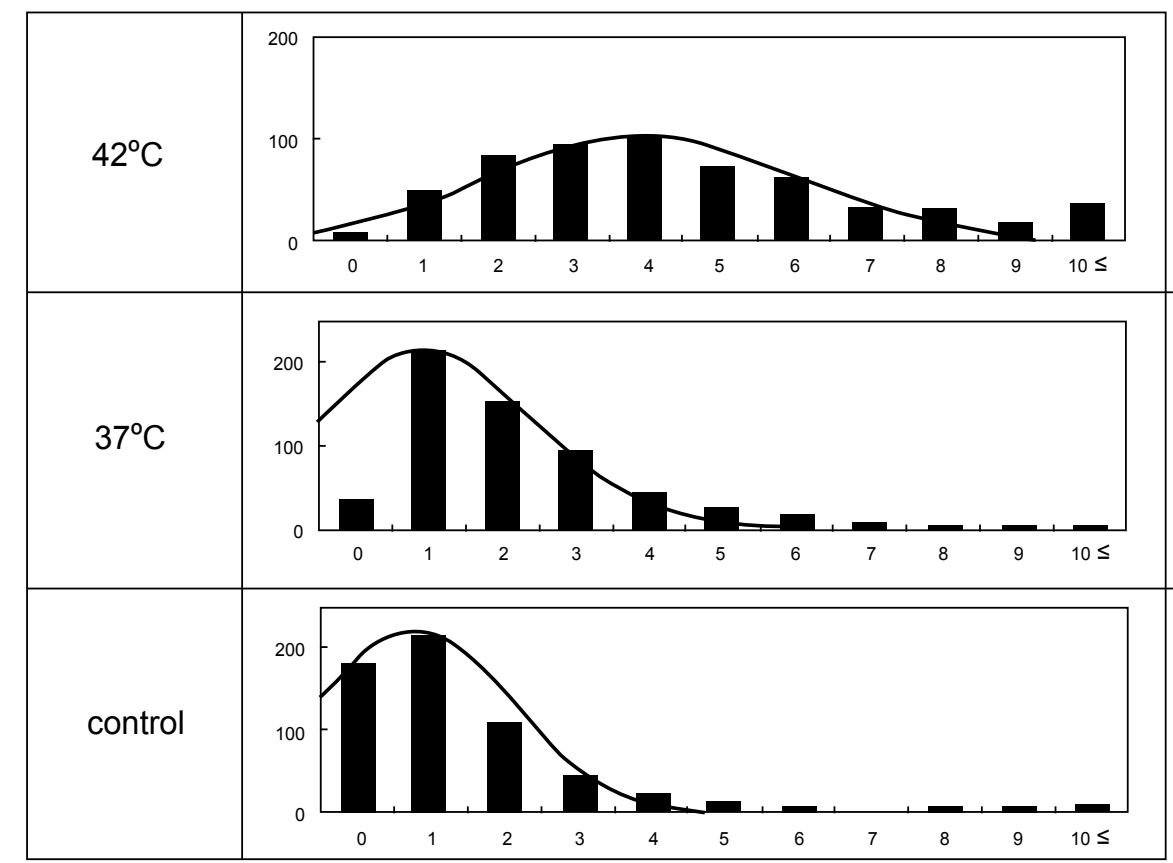

Figure 9: Histograms obtained from the arithmetic summation of all histograms shown in Figure 8, redrawn from Sugawara et al. [32]. The solid lines show the computed curve obtained by the least-squares method using a Gaussian curve. The resulting Gaussian constants are summarized in the text. 
Citation: Sugawara Y, Shigemasa Y, Hayashi Y, Abe Y, Ohgushi I, et al. (2013) New Mode (Molecular-Sensing) of Heinz Body Formation Mechanisms Inherent in Human Erythrocytes: Basis for Understanding of Clinical Aspects of Drug-Induced Hemolytic Anemia and the Like. J Bioanal Biomed 5: 036-056. doi:10.4172/1948-593X.1000078

the fluidity or rheology of blood [45]. This has subsequently been implemented in numerous studies [45-52]. A MC-FAN includes a characteristic $\mathrm{V}$-shaped groove array in an integral circuit with 8,736 flow paths (width, $7 \mu \mathrm{m}$; length, $30 \mu \mathrm{m}$; depth, $4.5 \mu \mathrm{m}$ ) engraved on a $15 \times 15 \times 0.5-\mathrm{mm}$ single-crystal silicon substrate using an anisotropic etching technique. The array is housed in a cylinder. This equipment enables observation of red cells passing through individual microchannel arrays by use of an inverted metallographic microscope, as well as to evaluate blood fluidity through the groove array in terms of the transit time of the blood sample for a given transit sample volume. Flow rate can be determined by timing when the meniscus of the blood sample crosses graduation marks at $10-\mu \mathrm{L}$ intervals from $0 \mu \mathrm{L}$ to $100 \mu \mathrm{L}$. The transit sample volume is therefore equivalent to the loss of the blood sample within the cylinder. Here we look into our in vitro findings on blood fluidity during mild heating using a MC-FAN (HR300; Hitachi Haramachi Electronics Co., Ibaraki, Japan) [32,33].

Donors were male or female student volunteers from the Prefectural University of Hiroshima (Hiroshima, Japan) and were aged 18-22 years. All volunteers were aware of the aims and procedures of the study. They gave their written informed consent to participate. The study protocol was approved by the Ethical Review Board of the Prefectural University of Hiroshima. Nine aliquots of samples of freshly drawn venous blood (10 $\mathrm{mL}$ in total) were obtained from healthy donors and mixed with one aliquot of $3.2 \%$ sodium citrate $\left(\mathrm{Na}_{3} \mathrm{C}_{6} \mathrm{H}_{5} \mathrm{O}_{7} \cdot 2 \mathrm{H}_{2} \mathrm{O}\right)$ or $3.8 \%$ sodium citrate $\left(\mathrm{Na}_{3} \mathrm{C}_{6} \mathrm{H}_{5} \mathrm{O}_{7} \cdot 5 \mathrm{H}_{2} \mathrm{O}\right)$. Blood samples were centrifuged at $400 \times g$ for $10 \mathrm{~min}$ at $0-4^{\circ} \mathrm{C}$ to eliminate the possibility of interference with blood fluidity measurements caused by platelet aggregation onto microchannel flow paths. The supernatant (platelet-rich plasma (PRP)) was

(a)

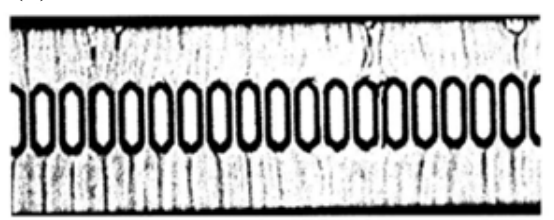

(b)

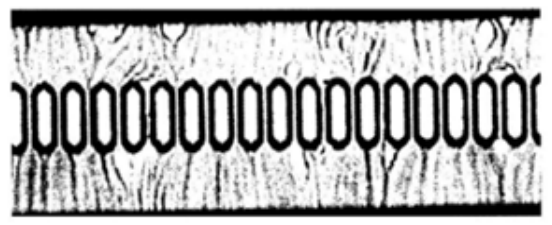

(c)

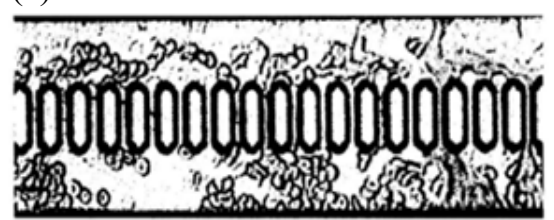

Figure 10: Microscopic details of blood samples passing through individual micro-channel arrays of the micro-channel array flow analyzer (MC-FAN), redrawn from Sugawara et al. [33]. (a) View of a temperature-untreated sample with a transit time $=12.6 \mathrm{~s}$ and transit sample volume $=25 \mu \mathrm{L}$. (b) Identical temperature-untreated with a transit time $=27.8 \mathrm{~s}$ and transit sample volume $=$ $50 \mu \mathrm{L}$; (c) View of an identical blood sample to that in (a) and (b) but subjected to mild heating at $45^{\circ} \mathrm{C}$ for 30 min prior to application to MC-FAN with a transit time $=120.7 \mathrm{~s}$ and transit sample volume $=30 \mu \mathrm{L}$. then discarded using a narrow Teflon-lined capillary connected to a waterjet pump. The remainder (PRP-removed blood) was subjected to mild heating prior to application to the MC-FAN. A 2-mL aliquot was placed in a test tube and incubated in a water bath maintained at each desired temperature $\left( \pm 0.1^{\circ} \mathrm{C}\right)$ above $37^{\circ} \mathrm{C}$ for 30 min using a NESLAB temperature control system (Model RTE-100 or 111 or 210 or 221).

Using a $1-\mathrm{mL}$ disposable syringe and a thin catheter, $200 \mu \mathrm{L}$ of each temperature-treated blood sample were introduced into a groove array via the cylinder house, which was connected to the inlet hole. The sample was allowed to flow through the cylinder house by applying a pressure difference of $20 \mathrm{~cm} \mathrm{H}_{2} \mathrm{O}$. Red cells passing through individual micro-channel arrays were monitored using an inverted metallographic microscope, a video camera, and a video-recorder system. As shown in Figure 10a and 10b, microscopic images revealed good erythrocyte deformability in temperature-untreated samples subjected to MC-FAN. However, a marked decline in erythrocyte deformability was observed in blood samples treated at temperatures greater than $37^{\circ} \mathrm{C}$ for $30 \mathrm{~min}$. An example is shown in Figure 10c. Temperature-treated samples also demonstrated increased transit time for low transit sample volumes.

Figure 11 illustrates some examples of blood fluidity of temperaturetreated samples measured as transit time versus transit sample volume. These graphs show that erythrocyte deformability decreased with increasing temperature at temperatures above $37^{\circ} \mathrm{C}$, although there was considerable inter-individual variation. Blood was therefore obtained from a further six healthy donors, and temperature-treated samples compared with a temperature-untreated sample as a reference. The results were similar to those in Figure 11. Both sets of results $(n=10)$ are summarized in Table 2. The temperature-dependent decrease in erythrocyte deformability induced by mild heating was evaluated using the Student's $t$-test on the total sum of the difference in transit times between a given temperature-treated sample and each temperatureuntreated reference, with varying transit sample volumes $(20,40$ and $60 \mu \mathrm{L})$. Significant differences $(p<0.001)$ between treated and control samples were evident for all samples treated at $45^{\circ} \mathrm{C}$ with transit sample volumes of 20,40 and $60 \mu \mathrm{L}$, and all samples treated at $42^{\circ} \mathrm{C}$ with transit sample volumes of 20,40 and $60 \mu \mathrm{L}$. To adequately show the results of Figure 11, significant differences $(p<0.001)$ of the samples treated at $45^{\circ} \mathrm{C}$ (i.e., two-point lines) and $42^{\circ} \mathrm{C}$ (i.e., one-point lines) against the control samples (i.e., solid lines) are shown. Furthermore a triplicate-experiment was conducted for each of three healthy donors $(n=3)$ in terms of transit time versus transit sample volume, whereby blood fluidity was assessed by the measurements each being allowed an interval of two to three months (Figure 12). On the basis of these findings, we concluded that erythrocyte deformability decreased with increasing temperature of blood samples treated at temperatures more than $37^{\circ} \mathrm{C}$.

New Mode of Molecular Biosensing Mechanisms Inherent in Human Erythrocytes for Appreciation of Cell Aging and Determination of their Lifespan

Human red blood corpuscles survive in the circulation for an average of 120 days. Removal of aged and damaged red cells from the blood circulation is essential for its homeostasis. This prompts the question: how do human erythrocytes appreciate aging and determine their lifespan?

Through a series of studies described in the preceding section, we drew seven main conclusions. First, autoxidation of human $\mathrm{HbO}_{2}$ (the 
Citation: Sugawara Y, Shigemasa Y, Hayashi Y, Abe Y, Ohgushi I, et al. (2013) New Mode (Molecular-Sensing) of Heinz Body Formation Mechanisms Inherent in Human Erythrocytes: Basis for Understanding of Clinical Aspects of Drug-Induced Hemolytic Anemia and the Like. J Bioanal Biomed 5: 036-056. doi:10.4172/1948-593X.1000078

(a)

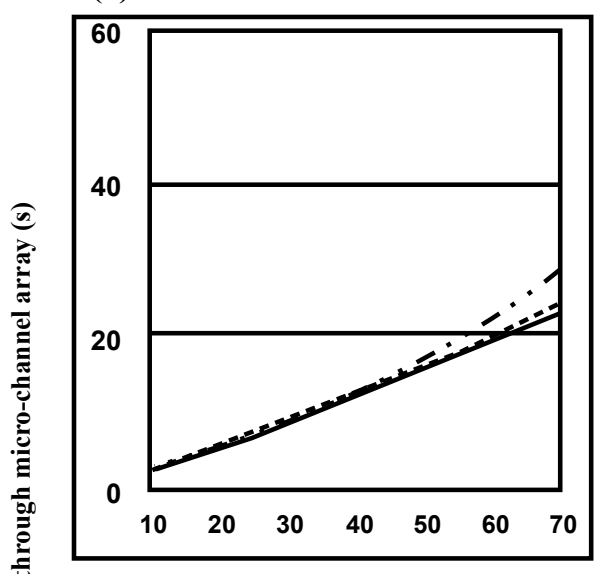

(b)

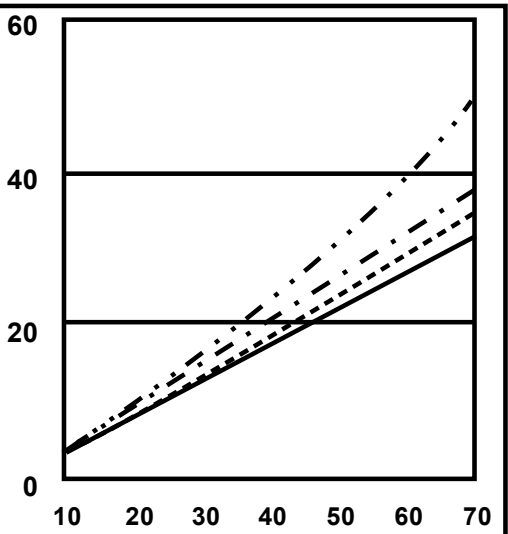

(c)

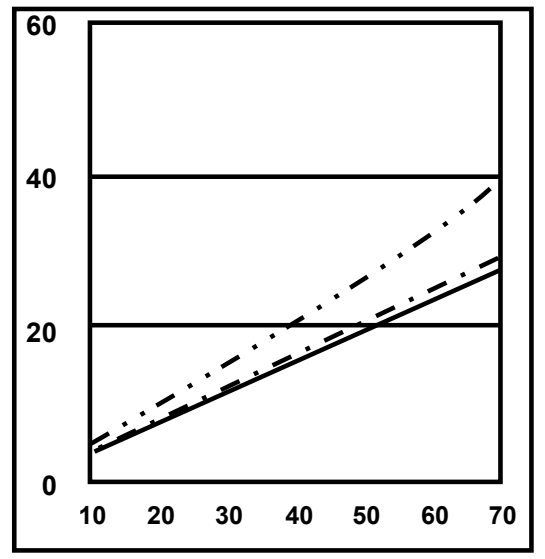

(d)

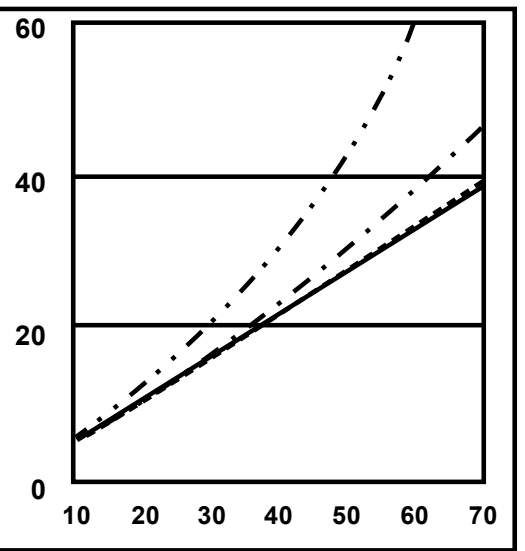

Transit blood sample volume through micro-channel array $(\mu \mathrm{l})$

Figure 11: Representative examples $(n=4)$ of blood fluidity measured in terms of transit time against transit sample volume, redrawn from Sugawara et al. [33]. Solid lines represent the temperature-untreated control; broken lines represent samples treated at $37^{\circ} \mathrm{C}$; one-point lines represent samples treated at $42^{\circ} \mathrm{C}$; two-point lines represent samples treated at $45^{\circ} \mathrm{C}$.

The mean \pm standard deviation of transit time of blood samples (s) for a given transit sample volume $(\mu \mathrm{L})$

\begin{tabular}{|c|c|c|}
\hline \multirow{2}{*}{} & \multicolumn{2}{|c|}{ Transit blood sample volume $(\mu \mathrm{L})$} \\
\hline Temperature-untreated reference & $20 \mu \mathrm{L}$ & $40 \mu \mathrm{L}$ \\
\hline Temperature-treated at $37^{\circ} \mathrm{C}$ & $8.0 \pm 1.08$ & $16.3 \pm 2.24$ \\
\hline Temperature-treated at $42^{\circ} \mathrm{C}$ & $7.8 \pm 1.35$ & $16.4 \pm 2.57$ \\
\hline Temperature-treated at $45^{\circ} \mathrm{C}$ & $8.5 \pm 1.38 * *$ & $18.3 \pm 2.94 * *$ \\
\hline
\end{tabular}

Table 2: Summary of the mean \pm standard deviation of transit time of blood samples (s) for a given transit sample volume ( $\mu \mathrm{L}$ ), redrawn from Sugawara et al. [33]. Prior to application to MC-FAN, blood samples were subjected to mild heating at $37^{\circ} \mathrm{C}, 42^{\circ} \mathrm{C}$ and $45^{\circ} \mathrm{C}$ for 30 min, respectively. The number of subjects was 10 . Significant differences $(p<0.001)$ of the temperature-treated samples against the temperature-untreated reference were shown as **.

reaction of which is inevitable in nature for all $\mathrm{O}_{2}$-binding proteins and which has been dealt with in the periphery of $\mathrm{Hb}$ research) seemed to be inseparably related to the instability of the $\mathrm{Hb}$ molecule and its degradation to hemichrome. Second, in terms of $\mathrm{pH}$ - and temperaturedependent hemichrome emergence observed by UV/VIS spectroscopy, $\mathrm{HbO}_{2}$ was supposed to be highly susceptible to hemichrome formation (even under physiological $\mathrm{pH}$ and temperature). Third, in contrast to the tetrameric human $\mathrm{HbO}_{2}$ as $\mathrm{O}_{2}$-carrying protein in the blood, the monomeric bovine heart $\mathrm{Mb}\left(\mathrm{MbO}_{2}\right)$ did not show any propensity for hemichrome formation over a wide $\mathrm{pH}$ range of 4.5 to 10.5 and over a wide temperature range from physiological to temperatures just before thermal unfolding. Fourth, in terms of $\mathrm{pH}$-dependent biphasic autoxidation $\left(\mathrm{k}_{\mathrm{A}}{ }^{\mathrm{f}}\right.$ for the initial fast oxidation and $\mathrm{k}_{\mathrm{A}}{ }^{\mathrm{s}}$ for the second oxidation) seen in acidic solutions, participation of a single dissociation group of an amino-acid residue (probably a His residue) with $\mathrm{pK}_{\mathrm{a}}=7.4$ (at $37^{\circ} \mathrm{C}$ ) appeared to have a key role in how the $\mathrm{Hb}$ 
Citation: Sugawara Y, Shigemasa Y, Hayashi Y, Abe Y, Ohgushi I, et al. (2013) New Mode (Molecular-Sensing) of Heinz Body Formation Mechanisms Inherent in Human Erythrocytes: Basis for Understanding of Clinical Aspects of Drug-Induced Hemolytic Anemia and the Like. J Bioanal Biomed 5: 036-056. doi:10.4172/1948-593X.1000078

(a)

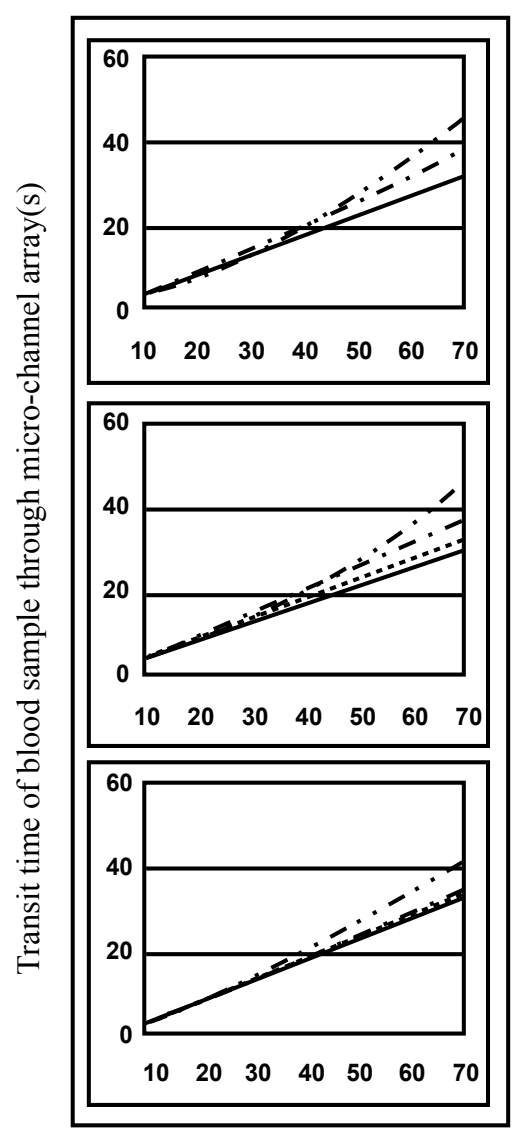

(b)
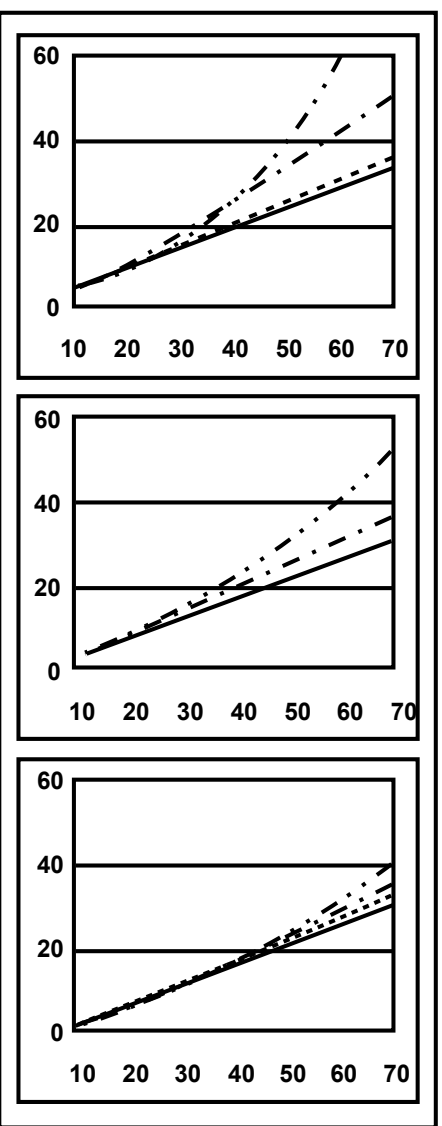

(c)
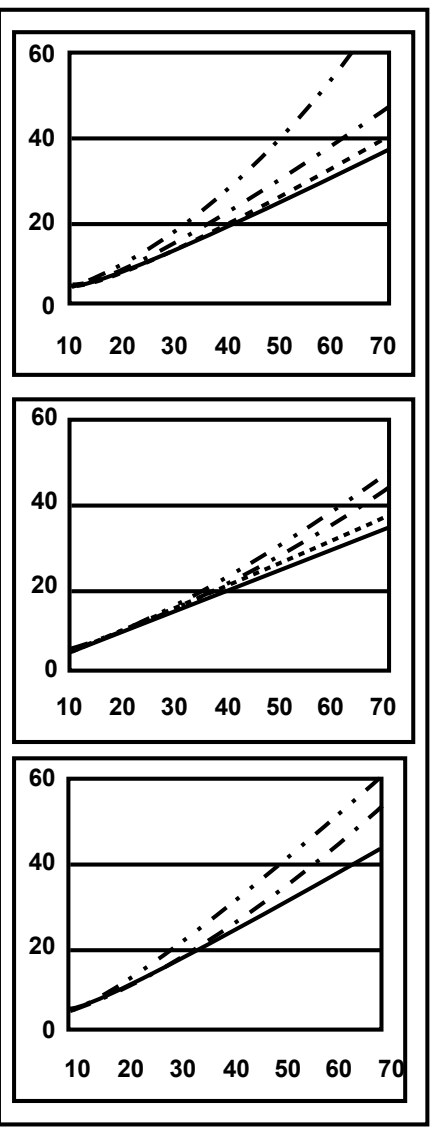

Transit blood sample volume through micro-channel array $(\mu \mathrm{l})$

Figure 12: Transit time versus transit sample volume plots obtained by a triplicate experiment. Blood fluidity was measured in three stages concerning three healthy donors ((a); (b); (c)), an interval of two to three months being allowed between measurements. Solid lines represent the temperature-untreated control; broken lines represent samples treated at $37^{\circ} \mathrm{C}$; one-point lines represent samples treated at $42^{\circ} \mathrm{C}$; two-point lines represent samples treated at $45^{\circ} \mathrm{C}$.

molecule can prompt the range of fast $\left(\mathrm{k}_{\mathrm{A}}{ }_{\mathrm{f}}\right)$ and slow $\left(\mathrm{k}_{\mathrm{A}}^{\mathrm{s}}\right)$ components against the $\mathrm{pH}$ values of the solutions. Fifth, the isolated $\alpha$ and $\beta$ chains were oxidized much more readily over the measured $\mathrm{pH}$ range (5-10.5) when compared with the respective rates of the parent molecules used as a reference. Sixth, using freshly drawn venous blood from healthy donors, exposure of red cells to acetylphenylhydrazine and subsequent staining with crystal violet revealed a greater abundance of Heinz bodies with increasing temperature if blood samples were subjected to mild heating at temperatures greater than $37^{\circ} \mathrm{C}$ for $30 \mathrm{~min}$. Finally, in vitro evaluation of blood fluidity during mild heating using a MCFAN demonstrated a marked decline in erythrocyte deformability with increasing temperature of blood samples if treated at temperatures more than $37^{\circ} \mathrm{C}$ for $30 \mathrm{~min}$.

In this section, we start to deal with the oxidative behavior (autoxidation) of the human $\mathrm{HbO}_{2}$ molecule. This is because autoxidation is inseparably related to the instability of the molecule and its degradation to hemichrome, relying upon the intrinsic tilting capability of the distal (E7) His residues (their bis-histidyl coordination proficiency to the heme iron). In $\mathrm{Hb}$ research, understanding of subunit interaction between the four $\mathrm{Hb}$ chains (how these explain cooperative
$\mathrm{O}_{2}$ binding) has been the primary focus [22-28]. Most of the emphasis is based on the distinct differences between deoxygenated and oxygenated quaternary structures as determined by X-ray diffraction [23-28]. The configuration of the residues lining the distal side of the heme pocket (where $\mathrm{O}_{2}$ binds and where geographical alteration can be made by oxygenation) is thought to play a part in controlling access of the ligand to the heme pocket. Nevertheless, the possibility of subunit interactions originating from or being transmitted via distal effects has (for the most part) been neglected [29]. Relatively little attention has been paid to the autoxidation of $\mathrm{HbO}_{2}$ (oxidation of ferrous heme iron by bound $\mathrm{O}_{2}$ ), even though autoxidation is inevitable in nature for all $\mathrm{O}_{2}$-binding heme proteins. It has been customary to deal with the "periphery" in $\mathrm{Hb}$ research.

Shikama [54-58] evaluated various mechanisms proposed for autoxidation involving $\mathrm{MbO}_{2}$ and $\mathrm{HbO}_{2}$. He demonstrated clearly that the autoxidation reaction does not simply involve the dissociative loss of $\mathrm{O}_{2}^{--}$from $\mathrm{HbO}_{2}$, but is instead caused by the nucleophilic displacement of $\mathrm{O}_{2}^{--}$from $\mathrm{HbO}_{2}$ by a water molecule or a hydroxyl ion that enters the heme pocket from the surrounding solvent. The iron is thus converted to the ferric met form, and the water molecule or hydroxyl ion remains 
Citation: Sugawara Y, Shigemasa Y, Hayashi Y, Abe Y, Ohgushi I, et al. (2013) New Mode (Molecular-Sensing) of Heinz Body Formation Mechanisms Inherent in Human Erythrocytes: Basis for Understanding of Clinical Aspects of Drug-Induced Hemolytic Anemia and the Like. J Bioanal Biomed 5: 036-056. doi:10.4172/1948-593X.1000078

bound to $\mathrm{Fe}(\mathrm{III})$ at the sixth coordinate position to form the aqua- or hydroxide-met species. A generalized pathway for this $\mathrm{S}_{\mathrm{N}} 2$ mechanism can be written using $\mathrm{Mb}\left(\mathrm{MbO}_{2}\right)$ as an example:

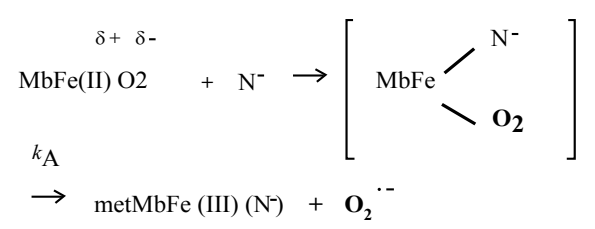

Here, $\mathrm{k}_{\mathrm{A}}$ represents the rate constant of anion-induced autoxidation with nucleophilic anion displacement. $\mathrm{N}^{-}$can be $\mathrm{SCN}^{-}, \mathrm{F}^{-}, \mathrm{OCN}^{-}, \mathrm{N}_{3}^{-}$, or $\mathrm{CN}^{-}$and, in vivo, it can be $\mathrm{H}_{2} \mathrm{O}$ or $\mathrm{OH}^{-}$. Anion-induced autoxidation with nucleophilic anion displacement of $\mathrm{O}_{2}$ results in an intermediate ferrous heme/anion complex that acts as an electron donor to displace oxygen. Shikama $[55,58]$ also demonstrated that, in vacuo, oxyhemeis inherently stable and unlikely to dissociate $\mathrm{O}_{2}{ }^{-}$spontaneously. Because $\mathrm{O}_{2}$ is a poor one-electron acceptor, a considerable thermodynamic barrier exists for such an electron transfer. In aqueous media (i.e., in contrast to in vacuo), oxyheme is subject to the nucleophilic attack of an entering water molecule (with or without proton catalysis) and to the attack of an entering hydroxide anion. These can cause irreversible oxidation of oxyheme to met-species with generation of $\mathrm{O}_{2}{ }^{-}$. $\mathrm{Mb}$ and $\mathrm{Hb}$ have therefore evolved with a globin moiety that can protect the $\mathrm{Fe}(\mathrm{II}) \mathrm{O}_{2}$ center from the easy access of a water molecule (including its conjugate ions $\mathrm{OH}^{-}$and $\mathrm{H}^{+}$).

In an aqueous protein-free system, Kao and Wang [58] reported the oxidation of dipyridine-ferrohemochrome by $\mathrm{O}_{2}$ using a stoppedflow technique. The main pathway was interpreted to involve one $\mathrm{O}_{2}$ molecule replacing one of the pyridine molecules in dipyridineferrohemochrome to form an oxyheme and then undergoing decomposition of ferrohemochrome to ferrihemochrome and $\mathrm{O}_{2}^{--}$. Unfortunately, the rate constant for this oxidation reaction could not be obtained because the concentration term of pyridine was always involved in its rate equation in a complicated manner. By numerical calculations, however, it follows that oxyheme autoxidation can proceed with a rate constant that is much higher than $1 \mathrm{~s}^{-1}$ in $0.1 \mathrm{M}$ buffer, $\mathrm{pH} 8.5$, at $25^{\circ} \mathrm{C}$. If such an oxyheme is placed in a protein matrix, it would be protected against the nucleophilic attack of the solvent water molecule or hydroxyl ion so as to reduce its autoxidation by a factor of approximately $10^{3}$. This was the case in our study with denatured $\mathrm{MbO}_{2}$ in $8 \mathrm{M}$ urea (the details of which can be referred to in Sugawara et al. [59]). A globin moiety can act as a "breakwater" in aqueous media even in denatured conditions with $8 \mathrm{M}$ urea. Furthermore, if an oxyheme is embedded in the native $\mathrm{Mb}$ architecture, $\mathrm{MbO}_{2}$ acquires remarkable stability against oxyheme autoxidation by a factor of approximately $10^{6}$.

With regard to oxyheme stability in human $\mathrm{HbO}_{2}$, the half-life $\left(\mathrm{t}_{1 / 2}\right)$ was only $1.5 \mathrm{~d}$ in $0.1 \mathrm{M}$ buffer and at physiological $\mathrm{pH}$ and temperature [34]. This is despite the fact that the content of metHb in normal red cells in situ $[60,61]$ has been maintained to be less thanor equal to $1 \%$ as a consequence of a NADH-dependent reducing system that can reduce the ferric-metHb resulting from autoxidation to deoxy-ferrous $\mathrm{Hb}$ [57]. However, as compared with the rates of monomeric mammalian Mbs, human $\mathrm{HbO}_{2}$ seemed to be 2.2-3.6 times more stable against autoxidation (probably owing to its tetrameric architecture). Even though the autoxidation rate is a function of $\mathrm{pH}$ and temperature, the observed first-order rate constant was $0.0023 \mathrm{~h}^{-1}\left(12.6 \mathrm{~d}\right.$ for $\left.t_{1 / 2}\right)$ for human $\mathrm{HbO}_{2}$ autoxidation under the conditions of $0.1 \mathrm{M}$ buffer at $\mathrm{pH}$ 7.2 and $25^{\circ} \mathrm{C}$ in our study [35] because this value was calculated from the first rapid phase. Conversely, the relevant values of the monomeric mammalian Mbs were $0.0082 \mathrm{~h}^{-1}\left(3.5 \mathrm{~d}\right.$ for $t_{1 / 2}$ ) for human $\mathrm{MbO}_{2}$, $0.0072 \mathrm{~h}^{-1}\left(4.0 \mathrm{~d}\right.$ for $\left.t_{1 / 2}\right)$ for bovine $\mathrm{MbO}_{2}$, and $0.0050 \mathrm{~h}^{-1}(5.8 \mathrm{~d}$ for $t_{1 / 2}$ ) for sperm-whale $\mathrm{MbO}_{2}$ under the same conditions used for human $\mathrm{HbO}_{2}$.

In our experiments, tetrameric human $\mathrm{HbO}_{2}$ showed a biphasic autoxidation curve in acidic solutions in terms of the $-\ln \left(\left[\mathrm{HbO}_{2}\right]_{t} /\right.$ $\left.\left[\mathrm{HbO}_{2}\right]_{0}\right)$ versus time plot (Figure $4 \mathrm{a}$ ); an initial rapid reaction $\left(\mathrm{k}_{\mathrm{A}}{ }^{\mathrm{f}}\right)$ could be followed with a slower second phase $\left(\mathrm{k}_{\mathrm{A}}{ }^{\mathrm{s}}\right)$. The difference in the rates between $\mathrm{k}_{\mathrm{A}}{ }^{\mathrm{f}}$ and $\mathrm{k}_{\mathrm{A}}{ }^{s}$ decreased with increasing $\mathrm{pH}$ values of solutions, and finally disappeared (i.e., $\mathrm{k}_{\mathrm{A}}{ }^{\mathrm{f}}$ equal to $\mathrm{k}_{\mathrm{A}}{ }^{s}$ ) if the $\mathrm{pH}$ of the solutions was more than 8 and became $\mathrm{k}_{\mathrm{A}}{ }^{\mathrm{f}}$ equal to $\mathrm{k}_{\mathrm{A}}{ }^{s}$. This finding leads to certain questions: how does the $\mathrm{Hb}$ molecule prompt the range of fast $\left(\mathrm{k}_{\mathrm{A}}^{\mathrm{f}}\right)$ and slow $\left(\mathrm{k}_{\mathrm{A}}^{s}\right)$ components in acidic solutions? How does the molecule provoke $\mathrm{k}_{\mathrm{A}}{ }_{\mathrm{f}}$ equal to $\mathrm{k}_{\mathrm{A}}{ }^{s}$ if the $\mathrm{pH}$ of solutions is more than 8 ? Does the biphasic autoxidation seen in acidic $\mathrm{pH}$ regions reflect a different rate owing to the individual $\mathrm{Hb}$ chains or the presence of valency hybrid intermediates such as $\left(\alpha^{2+} \beta^{3+}\right)_{2}$ and $\left(\alpha^{3+} \beta^{2+}\right)_{2}$ ?

A plot for the obtained values of $\mathrm{k}_{\mathrm{A}}{ }_{\mathrm{f}} / \mathrm{k}_{\mathrm{A}}{ }^{s}$ versus $\mathrm{pH}$ indicated that the reaction involves a single dissociation group of amino-acid residue with $\mathrm{pK}_{\mathrm{a}}=7.4\left(\right.$ at $\left.37^{\circ} \mathrm{C}\right)$ (Figure $4 \mathrm{~b}$ ), probably a His residue. In addition, study of rate measurement for the isolated $\alpha_{\mathrm{p}-\mathrm{MB}}$ and $\beta_{\mathrm{p}-\mathrm{MB}}$ chains (and $\alpha_{\mathrm{SH}}$ and $\beta_{\mathrm{SH}}$ chains) disclosed that once the constituted chains were isolated from the parent molecule, both separated chains could be oxidized much more rapidly to the ferric met-form over the measured $\mathrm{pH}$ range (5-10) when compared with the respective rates $\left(\mathrm{k}_{\mathrm{A}}{ }_{\mathrm{f}}\right.$ and $\left.\mathrm{k}_{\mathrm{A}}{ }^{\mathrm{s}}\right)$ of the parent molecules calculated from biphasic autoxidation curves as a reference (Figure 5). Also, there were no practical differences regarding the rate between the isolated individual chains (Figure 5). These findings may indicate that the individual chains have acquired considerable resistance to oxyheme autoxidation in their tetrameric protein architecture. It was also suggested that human $\mathrm{HbO}_{2}$ seems to have acquired a "pH-sensitive molecular device" as a consequence of development of the tetrameric protein architecture. Hence, the molecule shows remarkable stability against oxyheme autoxidation more than in cases of isolated individual chains from the parent molecules and monomeric mammalian Mbs.

Moreover, our recent measurements (UV/VIS spectrophotometry, isoelectric-focusing electrophoresis, and polyacrylamide gel electrophoresis) for autoxidation of human $\mathrm{HbO}_{2}$ [33] revealed that only two valency hybrids, i.e., $\left(\alpha^{3+} \beta^{2+}\right)_{2}$ and $\left(\alpha^{2+} \beta^{3+}\right)_{2}$, emerged in the tetrameric $\mathrm{HbO}_{2}$ autoxidation, even though, in theory, seven species of valency hybrids can be in existence during the reaction time course. These species are $\left(\alpha^{2+} \alpha^{2+} \beta^{3+} \beta^{2+}\right),\left(\alpha^{3+} \alpha^{2+} \beta^{2+} \beta^{2+}\right),\left(\alpha^{2+} \beta^{3+}\right),\left(\alpha^{3+} \beta^{2+}\right),\left(\alpha^{2+} \alpha^{3+} \beta^{2+} \beta^{3+}\right),\left(\alpha^{2+} \alpha^{3+} \beta^{3+} \beta^{3+}\right)$ and $\left(\alpha^{3+} \alpha^{3+} \beta^{3+} \beta^{2+}\right)$. These had satisfactory-to-good consistency with those reported by Tomoda et al. [15,62-67]. Computer simulations on the basis of these measurements (UV/VIS spectrophotometry, isoelectric-focusing electrophoresis, and polyacrylamide gel electrophoresis) indicated that the relevant concentration progress curves derived from the subsequent tentative model could explain not only aspects of the spectrophotometric changes in terms of the- $\ln \left(\left[\mathrm{HbO}_{2}\right]_{t} /\left[\mathrm{HbO}_{2}\right]_{0}\right)$ versus time plot, but also 
(a)
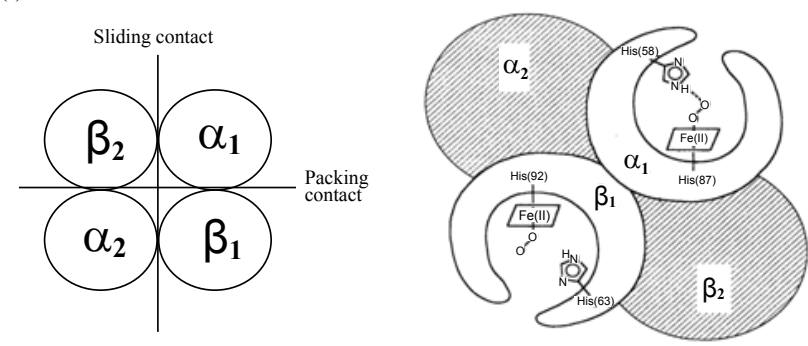

(b)

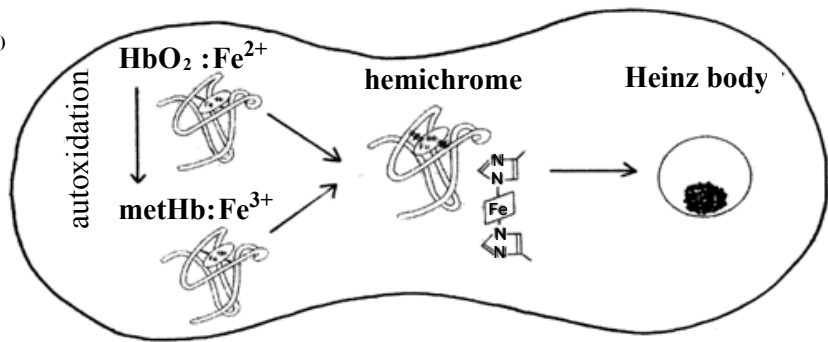

Figure 13: Schematic representation of the role of the $\alpha_{1}-\beta_{1}$ (and $\alpha_{2}-\beta_{2}$ ) interface in human $\mathrm{HbO}_{2}$.(a) The leftfigure shows a molecular dyad axis of $\mathrm{Hb}$ tetramer (which is perpendicular to the plane of the figure) relating the $\alpha_{1} \beta_{1}$ dimer to the $\alpha_{2} \beta_{2}$ dimer and consisting of the two different types of $\alpha \beta$ contacts: one is the $\alpha_{1}-\beta_{1}$ (and $\alpha_{2}-\beta_{2}$ ) (packing contact); and the other is the $\alpha_{1}-\beta_{2}$ (and $\alpha_{2}-\beta_{1}$ ) (sliding contact). The right figure illustrates that the $\alpha_{1}-\beta$ (and $\alpha_{2}-\beta_{2}$ ) produces in the $\beta$ chain a tilting of the distal (E7) His residue, thereby preventing the proton-catalyzed displacement of $\mathrm{O}_{2}^{-}$by a solvent water molecule. (b) The figure demonstrates that depending on internal and extraneous circumstances of the erythrocyte including $\mathrm{pH}$ and temperature the $\alpha_{1}-\beta_{1}$ (and $\alpha_{2}-\beta_{2}$ ) interface produces a conformational constraint in the constituted chains via tilting of the distal His (E7) residues so as to cause degradation of the $\mathrm{Hb}$ molecule to hemichrome, and subsequent Heinz-body clustering within the erythrocyte. In the spleen, Heinz body-containing red cells become trapped and hence undergo hemolysis.

aspects of the associated isoelectric-focusing electrophoretic profiles and polyacrylamide gel electrophoretic profiles, respectively, as shown below.

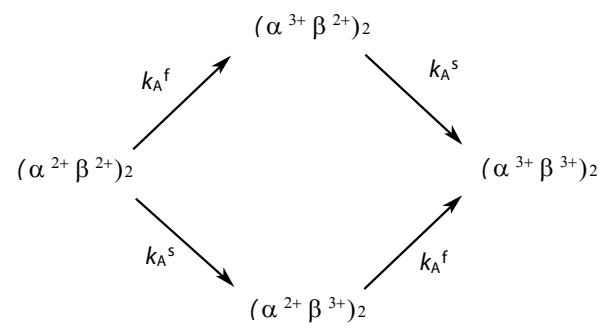

In an autoxidation reaction monitored in $0.05 \mathrm{M}$ phosphate buffer $(\mathrm{pH} 5.0)$ at $37^{\circ} \mathrm{C}$ in the presence of $20 \%(v / v)$ glycerol, the following kinetic constants and molar fraction of the initial fast component $(P)$ were established by least-squares fitting: $\mathrm{k}_{\mathrm{A}}{ }^{\mathrm{f}}=0.148 \mathrm{~h}^{-1}(4.7 \mathrm{~h}$ for $\left.t_{1 / 2}\right), \mathrm{k}_{\mathrm{A}}{ }^{s}=0.0208 \mathrm{~h}^{-1}\left(1.4\right.$ for $\left.t_{1 / 2}\right)$, and $P=0.51$. These findings led us to conclude that $\mathrm{k}_{\mathrm{A}}{ }_{\mathrm{f}}^{\mathrm{f}}$ represents intrinsic $\alpha$-chain oxidation and $\mathrm{k}_{\mathrm{A}}{ }^{s}$ reflects intrinsic $\beta$-chain oxidation, and that the $\beta$ chain manifests delayed autoxidation in human $\mathrm{HbO}_{2}$, which could be much more evident in acidic solutions.

Figure 13a shows our proposal with respect to this issue as reported in 1998 [30] and 2002 [31] in which we suggested a new function to the $\alpha_{1}-\beta_{1}$ (and $\alpha_{2}-\beta_{2}$ ) interface for stabilizing the $\mathrm{HbO}_{2}$ tetramer against acidic autoxidation. That is, the $\alpha_{1}-\beta_{1}$ (and $\alpha_{2}-\beta_{2}$ ) interface produces a conformational constraint in the $\beta$ chain whereby the distal (E7) His at position 63 is tilted slightly away from the bound $\mathrm{O}_{2}$ so as to prevent the proton-catalyzed displacement of $\mathrm{O}_{2}^{--}$from the $\mathrm{Fe}(\mathrm{II}) \mathrm{O}_{2}$ center by entrance of a water molecule. The $\beta$ chain thus acquires a remarkably delayed oxidation rate in the $\mathrm{HbO}_{2}$ tetramer. This is the origin of the chain heterogeneity seen in acidic solutions of $\mathrm{HbO}_{2}$ autoxidation.

The most recent refinement of the crystallographic structure of human $\mathrm{HbO}_{2}$ (where the $\mathrm{O}_{2}$ molecule is clearly visible in the highresolution electron density maps) demonstrated that the hydrogen bond made by His E7 $\beta$ (i.e., $\beta 63 \mathrm{His}$ ) is much weaker than that made by His E7a (i.e., a58His). However, it also substantiated that the geometry of the ligand and distal histidine is slightly different in the two subunits, with the $\mathrm{O}_{2}$ atom lying $2.7 \pm 0.1 \AA\left(10^{-1} \mathrm{~nm}\right)$ from the $\mathrm{N}^{\varepsilon}$ atom of the distal histidine in the a subunits, and 3.0- $\AA$ away in the $\beta$ subunits [68]. However, negligible changes were found for the $\alpha_{1}-\beta_{1}$ (and $\alpha_{2}-\beta_{2}$ ) interface with respect to examination of the crystal structure.

Similar phenomena suggesting participation of the $\alpha_{1}-\beta_{1}$ (and $\alpha_{2}-$ $\beta_{2}$ ) interface (i.e., participation of the inherent tilting capability of the distal (E7) His residues of the $\mathrm{Hb}$ molecule) garnered our interest. Our UV/VIS spectroscopic study suggested that human $\mathrm{HbO}_{2}$ was highly susceptible to hemichrome formation even under physiological $\mathrm{pH}$ and temperature (Figure 1 and $2 \mathrm{a}$ ) and, once isolated from the tetrameric parent molecule, the $\alpha\left(\alpha_{\mathrm{p}-\mathrm{MB}}\right)$ and $\beta\left(\beta_{\mathrm{p}-\mathrm{MB}}\right)$ chains showed much higher susceptibilities to hemichrome when compared with the parent molecule (Figure 2b). In this regard, one must note that monomeric bovine heart $\mathrm{Mb}\left(\mathrm{MbO}_{2}\right)$ did not show a propensity for hemichrome formation over a wide range of $\mathrm{pH}$ (4.5-10.5) and temperature from physiological to temperatures just before thermal unfolding (Figure 3 ).

Heinz bodies are intra-erythrocytic inclusions of hemichrome formed as a result of $\mathrm{Hb}$ oxidation. They have been detected and characterized in drug-induced hemolytic anemia, defects in the intra-erythrocytic reducing system (e.g., G-6-PD deficiency), and in unstable $\mathrm{Hb}$ disease $[2,3]$. Using unstable $\mathrm{Hb}$ disease as an example, several unstable Hbs have been reported. Regarding the molecular pathogenesis of unstable $\mathrm{Hbs}$, it is known that the instability of labile $\mathrm{Hb}$ variants in patients can be attributed to amino-acid substitutions (or deletions). These disrupt and perturb the $\mathrm{Hb}$ structure via interference with $\alpha$-helix formation, disruption of heme binding, or altered $\alpha_{1}$ $\beta_{1}$ (and $\alpha_{2}-\beta_{2}$ ) or $\alpha_{1}-\beta_{2}$ (and $\alpha_{2}-\beta_{1}$ ) contacts [2]. The consequent changes in circulating red cells in patients with unstable $\mathrm{Hb}$ disease include an inherent tendency towards irreversible denaturation of $\mathrm{Hb}$ or globin due to a defect in the amino-acid composition of labile $\mathrm{Hb}$ molecules, a continuous tendency toward hemichrome formation, precipitation or aggregation of $\mathrm{Hb}$ molecules resulting in buildup of the molecules to form Heinz bodies, and hemolysis.

Exposure of red cells to acetylphenylhydrazine and subsequent staining with crystal violet also revealed a greater abundance of Heinz bodies within G-6-PD-deficient cells compared with that in normal cells [69,70]. In addition, Sear et al. [71] and Campwala and Desforges [72] reported that Heinz bodies often appeared in normal-aging red cells, and that this age-related appearance of Heinz bodies was particularly pronounced in splenectomized individuals [73]. According to several authors $[1,74,75]$, aged or damaged red cells affected by drugs may be "filtered off" by the spleen irrespective of whether or not they contain Heinz bodies in a similar manner to the filtering-off of red blood cells in patients with unstable $\mathrm{Hb}$ caused by unstable $\mathrm{Hb}$ hemolytic anemia.

Using freshly drawn venous blood from healthy donors, we found that the number of Heinz bodies formed in red cells increased with increasing temperature when blood samples were subjected to mild heating at temperatures greater than $37^{\circ} \mathrm{C}$ for 30 min (Figures 6-9). 
Under identical conditions of mild heating, we measured blood fluidity using a MC-FAN [32,33] because it involves a characteristic V-shaped groove array with micro flow paths (width, $7 \mu \mathrm{m}$; length, $30 \mu \mathrm{m}$; depth, $4.5 \mu \mathrm{m}$ ) engraved on a single-crystal silicon substrate in an integral circuit. When red cells passing through individual micro-channel arrays were monitored using an inverted metallographic microscope, images revealed good erythrocyte deformability when temperatureuntreated samples were subjected to the MC-FAN (Figure 10a and 10b)). Conversely, a marked decline in erythrocyte deformability was observed in blood samples treated at temperatures more than $37^{\circ} \mathrm{C}$ for $30 \mathrm{~min}$ (Figure 10c). Temperature-treated samples also demonstrated an increased transit time for low transit sample volumes (Figure 11 and 12, Table 2).We therefore concluded that erythrocyte deformability decreased with increasing temperature of blood samples treated at temperatures above $37^{\circ} \mathrm{C}$. The combination of our experimental findingsand in situ observations suggests that instability leading to hemichrome formation is not only a peculiarity of labile $\mathrm{Hb}$ variants but is also an innate characteristic of physiologically normal $\mathrm{Hb}$ molecules.

In our experiments, the occurrence of hemichrome can be described as follows:

$$
\mathrm{Hb}(\mathrm{II}) \mathrm{O}_{2} \stackrel{\mathrm{k}_{\mathrm{A}}}{\longrightarrow} \operatorname{metHb}(\mathrm{III})+4\left(\mathrm{O}_{2}{ }^{-}\right) \rightarrow \text { hemichrome }
$$

Taking into account the accepted framework of the $\mathrm{S}_{\mathrm{N}} 2$ mechanism for autoxidation [54-58] and the accepted framework for hemichrome formation [13] in physiological conditions, hemichrome can form as follows:

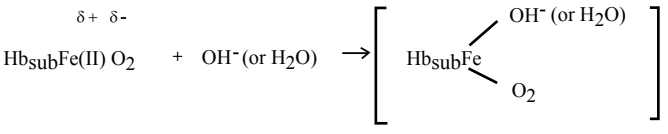

$$
\begin{aligned}
& \downarrow k_{\mathrm{A}} \\
& \mathrm{Hb}_{\text {sub }} \mathrm{Fe}(\mathrm{IIII}) \mathrm{OH}^{-}\left(\text {or } \mathrm{H}_{2} \mathrm{O}\right)+\mathrm{N}-(\mathrm{His}-\mathrm{E} 7) \\
& \downarrow_{k_{\mathrm{N}}} \\
& \text { metHbsubFe(III) (N) }
\end{aligned}
$$

In this scheme, $\mathrm{Hb}_{\text {sub }}$ represents each subunit of the $\mathrm{Hb}$ molecule. Nucleophilic displacement of $\mathrm{O}_{2}^{--}$by entry of a water molecule or a hydroxyl ion should be the rate-limiting step. Also, the subsequent conversion of the met form into hemichrome by a heme ligand $\left(\mathrm{N}^{-}\right)$ endogenous to the protein must proceed very quickly with the kinetic relationship $k_{\mathrm{N}}>>\mathrm{k}_{\mathrm{A}}$. The most probable candidate for $\mathrm{N}^{-}$in the $\mathrm{HbA}$ molecule is the $\mathrm{N}^{\varepsilon}$-nitrogen of the distal His (E7) (i.e., the only aminoacid side chain in the ligand pocket) of each subunit because $\mathrm{N}^{\varepsilon}$ nitrogen is located more than $4 \AA\left(10^{-1} \mathrm{~nm}\right)$ from the iron in $\mathrm{Hb}$, and is therefore not expected to coordinate in native $\mathrm{Hb}[13,76]$.

As described above, the content of metHb in normal erythrocytes $[61,62]$ has been reported to be less than or equal to $\%$ by a NADHdependent enzyme system [5-7]. This fact throws into question how erythrocytes can elicit the range of responses to hemichrome with such a small amount of metHb. We suggest that this can be achieved by intramolecular anion-induced nucleophilic displacement of molecular dioxygen via an intermediate ferrous heme/anion complex (a low-spin hemichrome) [17]. Such a reaction would follow the scheme:

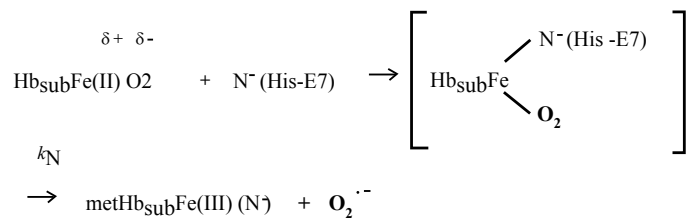

In this reaction, nucleophilic displacement can be caused within the heme pocket by the $\mathrm{N}^{\varepsilon}$-nitrogen of the distal His (E7) instead of nucleophilic incursion of the water molecule or the hydroxyl ion from outside the molecule. As indicated above, hemichrome formation occurs at every stage during the autoxidation of $\mathrm{HbO}_{2}$ (i.e., initial, intermediate, and final) as a function of the $\mathrm{pH}$ and temperature of the solution. While the reaction proceeds along this scheme, hemichromes may be derived not only from $\mathrm{HbO}_{2}$ species, but also from deoxyHb and metHb (Figure 13b). Vital hemichromes in erythrocytes in situ might arise from this intramolecular anion-induced nucleophilic displacement of $\mathrm{O}_{2}$ via an intermediate ferrous heme/anion complex.

Our electron paramagnetic resonance (EPR) measurement study [30] showed a low-spin spectrum for the resulting oxidation products of isolated $\beta$ chains with values of $g_{1}=2.77, g_{2}=2.27$, and $g_{3}=1.68$, in addition to the usual aquo-met species with $g$ values of 5.86 and 1.99 under a magnetic field of $0-500 \mathrm{mT}$ at $8.0 \mathrm{~K}$ in $10 \mathrm{mM}$ maleate buffer ( $\mathrm{pH}$ 6.2) and in the presence of 50\% ( $v / v)$ glycerol. According to Rifkind et al. [13], such low-spin complexes characterized by the highest $g$ values in the range 2.83-2.75 and the lowest $g$ values in the range 1.69-1.63 have been designated as "complex B", thereby indicating the crystal field parameters of the reversible hemichrome (i.e., a waterretained bis-histidine complex). The molar fraction of the hemichrome (complex B) in the oxidized $\beta$ chains was estimated to be $85 \%$ at $\mathrm{pH} 6.2$ because a low-spin species was in equilibrium with a high-spin species corresponding to the usual aquo-met species.

Interestingly, recent crystallographic and EPR spectroscopic studies concerning tetrameric Hbs isolated from the Antarctic fish species Trematomusbernacchii, Trematomusnewnesi, and Gymnodracoacuticep show that endogenous coordination at the sixth coordination site of the heme iron could be the bis-histidyl adducts in the ferric state in the solid and solution state [18,77-79]. In Antarctic fish, isolated $\mathrm{Hbs}$ are oxidized readily at room temperature to a partial hemichrome state in which only the iron of the $\beta$ chain is bonded to the distal His. Such bis-histidyl coordination was also discovered in the crystals of horse metHb exposed to acidic $\mathrm{pH}$ (where the proximal His [His87(F8)a] and a water molecule are the axial heme ligands) to the hemichrome (bis-histidine) form (in which the proximal His and the distal His [His58(E7)a] are the axial heme ligands) [80]. In the case of horse metHb, the bis-histidyl coordination was seen in a chains but not in $\beta$ chains. These crystal structures suggest a different binding state of $\alpha$ and $\beta$ chains as well as a different pathway to hemichrome.

As described above, the $\alpha_{1}-\beta_{1}$ (and $\alpha_{2}-\beta_{2}$ ) interface seemed to have dual faces. One is for stabilizing the $\mathrm{HbO}_{2}$ tetramer against the acidic autoxidation and the other is for controlling the fate (removal) of its own erythrocyte from the blood circulation. The $\alpha_{1}-\beta_{1}$ (and $\alpha_{2}-\beta_{2}$ ) interface produces a conformational constraint in the constructed chains of the $\mathrm{Hb}$ molecule via tilting of the distal (E7) His residues, i.e., $\alpha 58 \mathrm{His}$ (E7) in the $\alpha$ chain and $\beta 63 \mathrm{His}$ (E7) in the $\beta$ chain. It was also shown that the $\alpha_{1}-\beta_{1}$ (and $\alpha_{2}-\beta_{2}$ ) interface appears to have a $\mathrm{pH}$-sensor and a temperature-sensor. By virtue of these endowments, it seemed that $\mathrm{Hb}$ molecules can accomplish their roles not only as suitable $\mathrm{O}_{2}$ carriers between the lungs and tissues but also as equipped "molecular sensors" within the erythrocyte to control the fate (removal) of their own erythrocytes from the blood circulation depending on internal and extraneous circumstances, including $\mathrm{pH}$ and temperature (Figure 13).

Regarding the latter issue, normal erythrocytes develop Heinz bodies late in their lifespan. A wide variety of biochemical changes have 
been reported to accompany the aging of red cells [81]. These include carboxymethylation of proteins, activation of proteases, glycosylation of proteins, loss of membrane area, decline in changes in the ratio of bands $4.1 \mathrm{a}$ to $4.1 \mathrm{~b}$, increases in oxidized lipids and proteins, changes in the rheology and fragility of cells, changes in the exposure of cell-surface sugars, and gradual accumulation of $\mathrm{Ca}^{2+}$. Low [82] demonstrated that band-3 clustering might warrant closer scrutiny as a possible transducer of distress signals from the cytoplasm to the external surface of the cell because it can be caused by hemichrome binding, ATP depletion, malondialdehyde formation, $\mathrm{Ca}^{2+}$ accumulation, oxidative crosslinking, or weakening of the skeletal membrane. It is known that hemichromes formed within erythrocytes bind to the cytoplasmic portion of band 3 in the membrane. They then rapidly copolymerize with the soluble cytoplasmic domain of membrane band 3, forming an insoluble copolymer, followed by other changes involved in the pathogenesis of red-cell destruction [83-88]. The dominant role of band-3 clustering suggests that hemichrome formation-induced band3 clustering could also provide a key to controlling the fate of senescent and damaged red cells in the blood circulation [84].

\section{Discussion}

Heinz bodies are intra-erythrocytic inclusions of hemichrome formed from oxidized or denatured $\mathrm{Hb}$. They are commonly seen by phase contact microscopy as dark spots free in the cytoplasm or attached to the cytoplasmic surface of the erythrocyte membrane. Heinz bodies occur in red cells naturally under three distinct conditions. First, erythrocytes containing unstable $\mathrm{Hbs}$, especially $\mathrm{Hbs}$ with mutations near the heme site in the $\beta$ subunits, show elevated levels of Heinz bodies [2,3]. Second, Heinz bodies are seen in normal cells (containing normal $\mathrm{Hb}$ ) under conditions of oxidant stress. The oxidant stress can arise either in cells suffering from a diminished capacity to maintain intracellular reducing power, e.g., in G-6-PD and glutathione peroxidase deficiency diseases $[69,70]$. Third, Heinz bodies often appear in normal cells as they age $[71,72]$. This age-related appearance of Heinz bodies is especially pronounced in splenoectomized individuals where a major organ of senescent cell removal has been excised [73]. Heinz body formation, however, whether natural or drug induced or oxidant stress promoted or unstable $\mathrm{Hb}$ disease produced, has considered to be occurred by a similar mechanism.

From this point of view, in this article, we made an attempt to propose a new mode of Heinz body formation mechanisms on the basis of our experimental accomplishments and the related current interpretations and arguments, wherein the inherent tilting capability of the distal (E7) His residues (i.e., a58His (E7) in the $\alpha$ chain and $\beta 63 \mathrm{His}$ (E7) in the $\beta$ chain) of the $\mathrm{Hb}$ molecule plays a major role as well as involvement of the $\alpha_{1}-\beta_{1}$ (and $\alpha_{2}-\beta_{2}$ ) interface. As represented schematically in Figure 13, in this mechanisms, bishistidylcoordination proficiency to the heme iron of the distal (E7) His residuescan be prerequisite not only for an invocation to the end result of distal-side perturbations of the heme pocket against receipt for incoming stimuli around the molecule (i.e., $\mathrm{pH}$, temperature, oxidative stress), but also for the molecular biosensing mechanisms equipped in human erythrocytes for appreciation of cell aging and determination of their lifespan. Moreover this bis-histidyl coordination of the distal (E7) His residues to the heme iron can be manifested viacollaboration of the $\alpha_{1}-\beta_{1}$ (and $\alpha_{2}-\beta_{2}$ ) interface of the $\mathrm{Hb}$ molecule. Practically, vital hemichromes in erythrocytes can be achieved by intramolecular anioninduced nucleophilic displacement of molecular dioxygen $\left(\mathrm{O}_{2}\right)$ via an intermediate ferrous heme/anion complex (a low-spin hemichrome) by relying upon intrinsic tilting capability of the distal (E7) His residues (their bis-histidylcoordination proficiency to the heme iron):

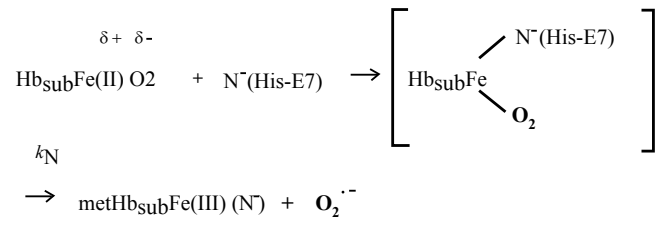

In this reaction, nucleophilic displacement can be caused within the heme pocket by the $\mathrm{N}^{\varepsilon}$-nitrogen of the distal His (E7) instead of nucleophilic incursion of the water molecule or the hydroxyl ion from outside the molecule. Hence, it was suggested that the sequential changes occurring within red corpuscles upon the removal of nonfunctional erythrocytes include: 1) receipt for internal and external stimuli (i.e.,pH, temperature, oxidative stressaround the erythrocyte) via the $\alpha_{1}-\beta_{1}$ (and $\alpha_{2}-\beta_{2}$ ) interface of the molecule; 2 ) an invocation to distal-side perturbations of the heme pocket as the end result of the receipt of incoming stimuli; 3) temporal bis-histidyl coordination of the distal (E7) His residues to the heme iron that lead to hemichrome (degradation of the $\mathrm{Hb}$ molecule); 4) hemichrome emergence and subsequent hemichrome precipitation and aggregation of the $\mathrm{Hb}$ molecules that lead to formation of Heinz bodies within the erythrocyte; and 5) hemolysis of Heinz body-containing red cell in the spleen.

Therefore, in the following, in an attempt to clarify how our hypothesis can explain a diverse status of Heinz body formation within the erythrocytes, we assess these (either in natural or drug induced or oxidant stress promoted or unstable $\mathrm{Hb}$ disease produced) one by one in detail.

First of all, we take up unstable $\mathrm{Hb}$ disease, as over 90 different unstable Hbs have been reported so far [2,3]. In establishing a diagnosis of unstable $\mathrm{Hb}$ disease, the heat denaturation test is considered to be the single most important procedure, in which a fresh hemolysate is diluted into 50 volumes of buffer solution and heated at $60^{\circ} \mathrm{C}$; at intervals the precipitates are removed from samples by centrifugation, and the optical density of the supernatant is measured. The reason of such instability even on mild heating (i.e., inclination toward accelerated degradation of $\mathrm{Hb}$ molecule to hemichrome resulting hemichrome precipitation and subsequent formation of Heinz bodieswithin the erythrocytes) is quite well understood at the molecular level, but there is still a lack of knowledge of the changes occurring during precipitation and ultimate cause of hemolysis.

Addition to this, the similarity to events observed in the oxidative hemolytic anemia suggests that the precipitation of unstable Hbs is accompanied by oxidative changes [2,3]. The oxidative hemolytic anemia arise either from formation of excess oxidizing products (as with acetylphenylhydrazine administration) or from breakdown of protective mechanisms against oxidants (as in G-6-PD deficiency). In either case, the end result is the same as with unstable Hbs; the precipitation of $\mathrm{Hb}$, the formation of Heinz bodies, and hemolysis.

In our hypothesis, incoming stimuli of the erythrocyte (e.g., $\mathrm{pH}$, temperature, oxidative stress), whether natural or drug induced or oxidant stress promoted or unstable $\mathrm{Hb}$ disease produced, can be transmitted ultimately to the distal-side perturbations of residues lining the distal side of the heme pocket via the $\alpha_{1}-\beta_{1}$ (and $\alpha_{2}-\beta_{2}$ ) interface, so that they let the distal (E7) His residues coordinate at the sixth coordination position of the heme iron to form a bis-histidyl complex. 
Citation: Sugawara Y, Shigemasa Y, Hayashi Y, Abe Y, Ohgushi I, et al. (2013) New Mode (Molecular-Sensing) of Heinz Body Formation Mechanisms Inherent in Human Erythrocytes: Basis for Understanding of Clinical Aspects of Drug-Induced Hemolytic Anemia and the Like. J Bioanal Biomed 5: 036-056. doi:10.4172/1948-593X.1000078

This temporal bis-histidyl coordination by virtue of the inherent tilting capability of the distal (E7) His residues (i.e., hemichrome emergence) in turn triggers a series of irreversible chemical reactions (including hemichrome formation-induced band-3 clustering and subsequent formation of Heinz bodies) that lead to the removal of non-functional erythrocytes from the blood circulation. Our hypothesis definitely demonstrates that there is positive correlation between the oxidative behavior of human $\mathrm{Hb}$, its inseparably related instability (accelerated inclination toward degradation of $\mathrm{Hb}$ molecule to hemichrome), the subsequent formation of Heinz bodies within the erythrocyte and its ultimate fate (hemolysis) even on mild conditions at close-tophysiological temperatures and $\mathrm{pH}$.

The defect in unstable Hbs involves important internal bonding amino acids, particularly those forming bonds with the heme group. Many of the mutants that occur at the $\alpha_{1}-\beta_{2}$ (and $\alpha_{2}-\beta_{1}$ ) interface have altered oxygen affinity, but the bulk of evidence suggests that the $\alpha_{1}-\beta_{1}$ (and $\alpha_{2}-\beta_{2}$ ) interface is much more important in maintaining the molecular stability of $\mathrm{Hb}$ than the $\alpha_{1}-\beta_{2}$ (and $\alpha_{2}-\beta_{1}$ ) interface. Hemolytic anemia results from substitutions affecting the $\alpha_{1}-\beta_{1}$ (and $\alpha_{2}-\beta_{2}$ ) interface or the heme pocket. If such mutations occur, the heme iron will be oxidized more readily, and a sequence of events leads to hemichrome formation and subsequent Heinz-body clustering in red cells that causes hemolytic anemia. Typical examples of such variants are summarized in Table 3. Surprisingly, almost all of these pathological mutations are found on the $\beta$ chain, especially in the $\alpha_{1}-\beta_{1}$ (and $\alpha_{2}-$ $\left.\beta_{2}\right)$ contact region: Tacoma [ $\beta 30(B 12) A r g \rightarrow$ Ser], Abraham Lincoln $[\beta 32(B 14) L e u \rightarrow$ Pro], Castilla [ $\beta 32(B 14) L e u \rightarrow$ Arg], Peterborough $[\beta 111(\mathrm{G} 13) \mathrm{Val} \rightarrow$ Phe], Madrid [ $\beta 115(\mathrm{G} 17)$ Ala $\rightarrow$ Pro], Khartoum $[\beta 124(\mathrm{H} 2)$ Pro $\rightarrow$ Arg], J. Guantanamo $[\beta 128(\mathrm{H} 6)$ Ala $\rightarrow$ Asp] and Leslie [ $\beta 131(\mathrm{H} 9) \mathrm{Gln} \rightarrow$ deleted]. In these Hbs, the $\alpha_{1}-\beta_{1}$ (and $\alpha_{2}-\beta_{2}$ ) interface would become loose or disruptive due to many different causes including: the insertion of proline (Abraham Lincoln, Madrid), the substitution with a too-small amino acid side chain (Tacoma) or a toolarge side chain (Peterborough), the introduction of a charged or very polar group (Castilla, Khartoum, J. Guantanamo), and the deletion of amino acid residue (Leslie).

The situation in patients with G-6-PD deficiency [2,3] can serve as another example. Red cells are known to be vulnerable to injury by endogenous and exogenous oxidants. Oxidants can be inactivated by reduced glutathione in erythrocytes with normal G-6PD activity because the pentose phosphate shunt supplies NADPH

\begin{tabular}{|c|c|}
\hline - E [B26(B8)Glu $\rightarrow$ Lys] & - Volga [327(B9)Ala $\rightarrow$ Asp] \\
\hline - Genova [328(B10)Leu $\rightarrow$ Pro] & - St. Louis [328(B10)Leu $\rightarrow$ GIn] \\
\hline - Tacoma [ß30(B12)Arg $\rightarrow$ Ser] & $\begin{array}{l}\text { - Abraham Lincoln [B32(B14)Leu } \rightarrow \\
\text { Pro] }\end{array}$ \\
\hline - Castilla [ß32(B14)Leu $\rightarrow$ Arg] & - Philly [B35(C1)Tyr $\rightarrow$ Phe] \\
\hline • Rush [ß3101(G3)Glu $\rightarrow$ Gln] & - Peterborough [ $\beta 111(\mathrm{G} 13) \mathrm{Val} \rightarrow \mathrm{Phe}]$ \\
\hline - Madrid [ß115(G17)Ala $\rightarrow$ Pro] & - Khartoum [ $\beta 124(\mathrm{H} 2)$ Pro $\rightarrow$ Arg] \\
\hline - J. Guantanamo $[\beta 128(\mathrm{H} 6)$ Ala $\rightarrow$ Asp] & - Wien $[\beta 130(\mathrm{H} 8) \mathrm{Tyr} \rightarrow \mathrm{Asp}]$ \\
\hline - Leslie $[\beta 131(\mathrm{H} 9) \mathrm{Gln} \rightarrow$ deleted] & - Torino [a43(CD1)Phe $\rightarrow$ Val] \\
\hline - L. Ferrara [a47(CD5)Asp $\rightarrow$ Gly] & - Setif [a94(G1)Asp $\rightarrow$ Tyr] \\
\hline - St. Lukes [a95(G2)Pro $\rightarrow$ Arg] & \\
\hline
\end{tabular}

Table 3: Unstable hemoglobin variants, showing sites of amino acid substitutions (or deletions), redrawn from Sugawara et al. [34]. Each individual row illustrates variant's name, the residue concerned (chain; number; position), and replacement (from $\rightarrow$ to), respectively. (which is required for glutathione recycling). In G-6-PD-deficient erythrocytes, however, the reduced glutathione cannot be restored, and the cells sustain irreversible oxidative damage. However, G-6PD deficiency produces symptoms only if the patient is exposed to an environmental factor that results in increased oxidative stress. Such stress includes antimalarials (e.g., primaquine, pamaquine, dapsone), sulfonamides, nitrofurantoin and phenacetin. The resulting crisis can lead to hemolysis of up to $25-30 \%$ of red cells within hours. However, the crisis is self-limited, and only the older population of red cells is destroyed. The mechanisms responsible for such an acute hemolytic crisis in patients taking these drugs cannot be explained on the basis of conventional views. Figure 13 suggests that this crisis could be triggered by fluctuations in endogenous and exogenous oxidative stress under the fragile pentose phosphate shunt.

Malaria provides the other example. This is a protozoal disease transmitted by the bite of female Anopheles mosquitoes (Plasmodium falciparum, $P$. malariae, $P$. vivax, and $P$. ovale). Blackwater fever syndrome is caused by infection with $P$. falciparum, and is characterized by repeated bouts of chills and fevers, severe intravascular hemolysis and anemia, jaundice, hemoglobinuria (black urine) and splenic enlargement [89-91]. Patients often develop fevers above $40^{\circ} \mathrm{C}$. A feature of this syndrome is that symptoms can be exacerbated in patients with G-6-PD deficiency as a result of taking quinine. In these patients, massive destruction of red cells infected by the parasite occurs, but similar numbers of normal erythrocytes are also ruptured, resulting in characteristic hemoglobinuria. The reason for the massive hemolysis of non-infected red cells is unclear. However, the possibility of a relationship between quinine ingestion and the associated massive hemolysis, as well as the relevance of G-6-PD deficiency, is addressed in Figure 13. Fevers above $40^{\circ} \mathrm{C}$, endogenous G-6-PD deficiency, and exogenous quinine ingestion represent conditions that induce acute hemolysis, thereby leading to massive blood loss and hemoglobinuria.

\section{Conclusions}

Cellular life is reliant upon rapid and efficient responses to internal and external conditions whereby basic molecular events associated with these processes are the structural transitions of the proteins (structural protein allostery) involved. The human Hb molecule $\left(\alpha_{2} \beta_{2}\right)$ holds a special position in these structural transitions. Hb has two types of $\alpha-\beta$ interface (i.e., $\alpha_{1}-\beta_{1}$ [and $\alpha_{2}-\beta_{2}$ ] and $\alpha_{1}-\beta_{2}$ [and $\left.\alpha_{2}-\beta_{1}\right]$ ). The latter $\alpha_{1}-\beta_{2}$ (and $\alpha_{2}-\beta_{1}$ ) interface is associated with cooperative $\mathrm{O}_{2}$ binding, and exhibits principal roles if the molecule goes from its deoxygenated to oxygenated quaternary structure. However, the role of the former $\alpha_{1}-\beta_{1}$ (and $\left.\alpha_{2}-\beta_{2}\right)$ interface has been unclear for a long time.

In this regard, important and intriguing observations have been accumulating, so that a new gaze can be focused on the $\alpha_{1}-\beta_{1}$ (and $\alpha_{2}-\beta_{2}$ ) interface. In this article, on the basis of our experimental accomplishments and the related current interpretations and arguments, we first proposed a new mode of Heinz body formation mechanisms, wherein the inherent tilting capability of the distal (E7) His residues(i.e., $\alpha 58 \mathrm{His}$ (E7) in the $\alpha$ chain and $\beta 63 \mathrm{His}$ (E7) in the $\beta$ chain) of the $\mathrm{Hb}$ molecule plays a major role as well as involvement of the $\alpha_{1}-\beta_{1}\left(\right.$ and $\alpha_{2}-\beta_{2}$ ) interface. Specifically, the suggested sequential changes occurring within the erythrocyte upon the removal of nonfunctional erythrocytes, whether natural or drug induced or oxidant stress promoted or unstable $\mathrm{Hb}$ disease produced, include: 1) receipt for internal and external stimuli around the erythrocyte (e.g., $\mathrm{pH}$, temperature, oxidative stress) via the $\alpha_{1}-\beta_{1}$ (and $\alpha_{2}-\beta_{2}$ ) interface of the molecule; 2) an invocation to distal-side perturbations of the heme 
Citation: Sugawara Y, Shigemasa Y, Hayashi Y, Abe Y, Ohgushi I, et al. (2013) New Mode (Molecular-Sensing) of Heinz Body Formation Mechanisms Inherent in Human Erythrocytes: Basis for Understanding of Clinical Aspects of Drug-Induced Hemolytic Anemia and the Like. J Bioanal Biomed 5: 036-056. doi:10.4172/1948-593X.1000078

pocket as the end result of the receipt of incoming stimuli; 3) temporal bis-histidylcoordination of the distal (E7) His residuesto the heme iron that lead to hemichrome (degradation of the $\mathrm{Hb}$ molecule); 4) hemichrome emergence and subsequent hemichrome precipitation and aggregation of the $\mathrm{Hb}$ molecules that lead to formation of Heinz bodies within the erythrocyte; and 5) hemolysis of Heinz bodycontaining red cell in the spleen.

Granting this new mode of Heinz body formation mechanisms to be basic premise, we then made an attempt to examine how this new mode of mechanisms can serve as a basis for deeper understanding of clinical aspects of drag-induced hemolytic anemia, defects in the intraerythrocytic reducing system and unstable $\mathrm{Hb}$ disease, in which the mechanisms for acute hemolytic crisis cannot be explained on the basis of conventional views. The followings were shown:

(1) Almost all of pathological mutations of unstable $\mathrm{Hbs}$ are found on the $\beta$ chain, especially in the $\alpha_{1}-\beta_{1}$ (and $\alpha_{2}-\beta_{2}$ ) contact region: Tacoma [ $\beta 30(\mathrm{~B} 12)$ Arg $\rightarrow$ Ser], Abraham Lincoln [ $\beta 32$ (B14)Leu $\rightarrow$ Pro], Castilla [ $\beta 32(B 14) L e u \rightarrow$ Arg], Peterborough $[\beta 111(\mathrm{G} 13) \mathrm{Val} \rightarrow$ Phe], Madrid $[\beta 115(\mathrm{G} 17)$ Ala $\rightarrow$ Pro], Khartoum $[\beta 124(\mathrm{H} 2)$ Pro $\rightarrow$ Arg],J. Guantanamo $[\beta 128(\mathrm{H} 6)$ Ala $\rightarrow$ Asp] and Leslie [ $\beta 131(\mathrm{H} 9)$ Gln $\rightarrow$ deleted].

(2) Acute hemolytic crisis observed in patients of G-6-PD deficiency while taking drugs such as antimalarials (e.g., primaquine, pamaquine, dapsone), sulfonamides, nitrofurantoin and phenacetin can be explained by increased oxidative stress against inadequate reduced glutathione levels in erythrocytes of the patients.

(3) Acute hemolytic crisis associated with black water fever syndrome of malarial patients caused by infection with Plasmodium falciparum can be also explained by fevers above $40^{\circ} \mathrm{C}$, endogenous G-6-PD deficiency, and exogenous quinine ingestion.

\section{References}

1. WEISS L (1962) The structure of fine splenic arterial vessels in relation to hemoconcentration and red cell destruction. Am J Anat 111: 131-179.

2. Winslow RM, Anderson WF (1978) The Hemoglobinopathies. In The Metabolic Basis of Inherited Disease. Stanbury JB, Wyngaarden JB, Fredricks DS Eds.; McGraw-Hill Book Company: New York, NY, USA, 1465-1507.

3. Weatherall DJ, Clegg JB, Higgs DR, Wood WG (1995) The Hemoglobinopathies. InThe Metabolic and Molecular Basis of Inherited Disease. Scriver CR, Beaudet AL, William SS, Valle D Eds.; McGraw-Hill Inc.: New York, NY, USA, Volume III, pp. 3413-3484.

4. Jacob HS (1970) Mechanisms of Heinz body formation and attachment to red cell membrane. Semin Hematol 7: 341-354.

5. Scott EM, Duncan IW, Ekstrand V (1965) The reduced pyridine nucleotide dehydrogenases of human erythrocytes. J Biol Chem 240: 481-485.

6. Hultquist DE, Passon PG (1971) Catalysis of methaemoglobin reduction by erythrocyte cytochrome B5 and cytochrome B5 reductase. Nat New Biol 229: 252-254.

7. Sugita Y, Nomura S, Yoneyama Y (1971) Purification of reduced pyridine nucleotide dehydrogenase from human erythrocytes and methemoglobin reduction by the enzyme. J Biol Chem 246: 6072-6078.

8. Rachmilewitz EA, Peisach J, Bradley TB, Blumberg WE (1969) Role of haemichromes in the formation of inclusion bodies in haemoglobin $\mathrm{H}$ disease. Nature 222: 248-250.

9. Rachmilewitz EA, Peisach J, Blumberg WE (1971) Studies on the stability of oxyhemoglobin $A$ and its constituent chains and their derivatives. J Biol Chem
246: $3356-3366$

10. Rachmilewitz EA (1974) Denaturation of the normal and abnormal hemoglobin molecule. SeminHematol 11: 441-462.

11. Winterbourn CC, Carrell RW (1974) Studies of hemoglobin denaturation and Heinz body formation in the unstable hemoglobins. J Clin Invest 54: 678-689.

12. Macdonald VW (1994) Measuring relative rates of hemoglobin oxidation and denaturation. Methods Enzymol 231: 480-490.

13. Rifkind JM, Abugo O, Levy A, Heim J (1994) Detection, formation, and relevance of hemichromes and hemochromes. Methods Enzymol 231: 449-480.

14. Brunori M, Falcioni G, Fioretti E, Giardina B, Rotilio G (1975) Formation of superoxide in the autoxidation of the isolated $\alpha$ and $\beta$ chains of human hemoglobin and its involvement in hemichrome precipitation. European Journal of Biochemistry 53: 99-104.

15. Tomoda A, Sugimoto K, Suhara M, Takeshita M, Yoneyama Y (1978) Haemichrome formation from haemoglobin subunits by hydrogen peroxide. Biochem J 171: 329-335

16. McDonald MJ, Turci SM, Mrabet NT, Himelstein BP, Bunn HF (1987) The kinetics of assembly of normal and variant human oxyhemoglobins. J Biol Chem 262: 5951-5956.

17. Sugawara Y, Kadono E, Suzuki A, Yukuta Y, Shibasaki Y, et al. (2003) Hemichrome formation observed in human haemoglobin A under various buffer conditions. Acta Physiol Scand 179: 49-59.

18. Vitagliano L, Vergara A, Bonomi G, Merlino A, Verde C, et al. (2008) Spectroscopic and crystallographic characterization of a tetrameric hemoglobin oxidation reveals structural features of the functional intermediate relaxed/ tense state. J Am Chem Soc 130: 10527-10535.

19. Perutz MF (1970) Stereochemistry of cooperative effects in haemoglobin. Nature 228: 726-739.

20. Perutz MF (1972) Nature of haem-haem interaction. Nature 237: 495-499

21. Perutz MF, Fermi G, Abraham DJ, Poyart C, Bursaux E (1986) Hemoglobin as a receptor of drugs and peptides: X-ray studies of the stereochemistry of binding. J Am Chem Soc 108: 1064-1078.

22. Imai K (1994) Adair fitting to oxygen equilibrium curves of hemoglobin. Methods Enzymol 232: 559-576

23. Baldwin J, Chothia C (1979) Haemoglobin: the structural changes related to ligand binding and its allosteric mechanism. J Mol Biol 129: 175-220.

24. Fermi G, Perutz MF (1981) Haemoglobin and Myoglobin. Volume 2, Clarendon Press: Oxford, UK

25. Dickerson RE, Geis I (1983) Hemoglobin: Structure, Function, Evolution and Pathology; The Benjamin/Cummings Publishing Co., Inc., Menlo Park, CA USA, 176 pages.

26. Perutz MF (1990) Mechanisms of Cooperativity and Allosteric Regulation in Proteins; CambridgeUniversity Press: Cambridge, UK.

27. Perutz MF, Wilkinson AJ, Paoli M, Dodson GG (1998) Thestereochemica mechanism of the cooperative effects in hemoglobin revisited. Annu Rev BiophysBiomol Struct 27: 1-34.

28. Borgstahl GE, Rogers PH, Arnone A (1994) The 1.8 A structure of carbonmonoxy-beta 4 hemoglobin. Analysis of a homotetramer with the $R$ quaternary structure of liganded alpha 2 beta 2 hemoglobin. J Mol Biol 236: 817-830.

29. Levy A, Sharma VS, Zhang L, Rifkind JM (1992) A new mode for heme-heme interactions in hemoglobin associated with distal perturbations. Biophys $\mathrm{J} 61$ 750-755.

30. Tsuruga M, Matsuoka A, Hachimori A, Sugawara Y, Shikama K (1998) The molecular mechanism of autoxidation for human oxyhemoglobin. Tilting of the distal histidine causes nonequivalent oxidation in the beta chain. J Biol Chem 273: 8607-8615.

31. Yasuda Jp, Ichikawa T, Tsuruga M, Matsuoka A, Sugawara Y, et al. (2002) The alpha 1 beta 1 contact of human hemoglobin plays a key role in stabilizing the bound dioxygen. Eur J Biochem 269: 202-211.

32. Sugawara Y, Hayashi Y, Shigemasa Y, Abe Y, Ohgushi I, et al. (2010) Molecular biosensing mechanisms in the spleen for the removal of aged and damaged red cells from the blood circulation. Sensors (Basel) 10: 7099-7121. 
Citation: Sugawara Y, Shigemasa Y, Hayashi Y, Abe Y, Ohgushi I, et al. (2013) New Mode (Molecular-Sensing) of Heinz Body Formation Mechanisms Inherent in Human Erythrocytes: Basis for Understanding of Clinical Aspects of Drug-Induced Hemolytic Anemia and the Like. J Bioanal Biomed 5: 036-056. doi:10.4172/1948-593X.1000078

33. Sugawara Y, Yamada M, Ueno E, Okazaki M , Okamoto A, et al. (2011) New roles assigned to the $\alpha_{1}-\beta_{1}$ (and $\alpha_{2}-\beta_{2}$ )interface of the human hemoglobin molecule from physiological to cellular. Appl Sci 1: 13-55.

34. Sugawara Y, Sakoda M, Shibata N, Sakamoto H (1993) Autoxidation of human hemoglobin: kinetic analysis of the pH-profile. Jpn J Physiol 43: 21-34.

35. Goto T, Shikama K (1974) Autoxidation of native oxymyoglobin from bovine heart muscle. Arch Biochem Biophys 163: 476-481.

36. Brooks J (1948) The oxidation of haemoglobin to methaemoglobin by oxygen J Physiol 107: 332-335.

37. Brooks J (1935) The oxidation of haemoglobin to methaemoglobin by oxygen II-The relation between the rate of oxidation and the partial pressure of oxygen. Proceedings of the Royal Society of London Series B, Biological Sciences 118: 560-570.

38. Mansouri A, Winterhalter KH (1973) Nonequivalence of chains in hemoglobin oxidation. Biochemistry 12: 4946-4949.

39. Tomoda A, Yoneyama Y, Tsuji A (1981) Changes in intermediate haemoglobins during autoxidation of haemoglobin. Biochem J 195: 485-492.

40. Hermans J Jr, Rialdi G (1965) Heat of ionization and denaturation of spermwhale myoglobin determined with a microcalorimeter. Biochemistry 4: 12771281.

41. Fasman GD (1976) Physical and chemical data. In Handbook of Biochemistry and Molecular Biology, 3rd edition, CRC Press: Cleveland, OH, USA, p. 220

42. Demetriou JA, Drewes, PA, Gin JB (1974) Enzymes. In Clinical Chemistry,2nd ed.; Henry, R.J., Cannon, D.C., Winkelmann, J.W., Eds.; Harper \& Row Publishers: New York, NY, USA 815-1001.

43. Bauer JD (1980) Laboratory investigation of hemoglobin. In Gradwohl's Clinical Laboratory Methods and Diagnosis. Sonnenwirtyh, AC Jarett, L., Eds 809-901.

44. Kikuchi Y, Sato K, Ohki H, Kaneko T (1992) Optically accessible microchannels formed in a single-crystal silicon substrate for studies of blood rheology. Microvasc Res 44: 226-240.

45. Suganuma $\mathrm{H}$, Inakuma $\mathrm{T}$, Kikuchi $\mathrm{Y}$ (2002) Amelioratory effect of barley tea drinking on blood fluidity. J NutrSciVitaminol (Tokyo) 48: 165-168.

46. Begum AN, Terao J (2002) Protective effect of quercetin against cigarette tar extract-induced impairment of erythrocyte deformability. J Nutr Biochem 13: 265-272.

47. Kamada H, Hattori K, Hayashi T, Suzuki K (2004) In vitro evaluation of blood coagulation activation and microthrombus formation by a microchannel array flow analyzer. Thromb Res 114: 195-203.

48. Sumino H, Nara M, Seki K, Takahashi T, Kanda T, et al. (2005) Effect of antihypertensive therapy on blood rheology in patients with essential hypertension. J Int Med Res 33: 170-177.

49. Watanabe N, Kimura F, Kojima F, Endo, Y, Fujimoto, K et al. (2005) Effect of sterols in dietary fats on whole blood viscosity of stroke-prone spontaneously hypertensive rats (SHRSP) J Oleo Sci 54: 1-6.

50. Muranaka Y, Kunimoto F, Takita J, Sumino H, Nara M, et al. (2006) Impaired blood rheology in critically ill patients in an intensive care unit. J Int Med Res 34: 419-427

51. Seki K, Sumino H, Nara M, Ishiyama N, Nishino M, et al. (2006) Relationships between blood rheology and age, body mass index, blood cell count, fibrinogen, and lipids in healthy subjects. Clin HemorheolMicrocirc 34: 401-410.

52. Watanabe N, Watanabe Y, Kumagai M, Fujimoto K (2009) Administration of dietary fish oil capsules in healthy middle-aged Japanese men with a high level of fish consumption. Int J Food SciNutr 60 Suppl 5: 136-142.

53. Shikama K (1985) Nature of the FeO2 bonding in myoglobin: an overview from physical to clinical biochemistry. Experientia 41: 701-706

54. Shikama K (1988) Stability properties of dioxygen-iron (II) porphyrins: An overview from simple complexes to myoglobin. Coord Chem Rev 83: 73-91.

55. Shikama K (1990) Autoxidation of oxymyoglobin: a meeting point of the stabilization and the activation of molecular oxygen. Biol Rev Camb Philos Soc 65: 517-527.

56. Shikama K (1998) The Molecular Mechanism of Autoxidation for Myoglobin and
Hemoglobin: A Venerable Puzzle. Chem Rev 98: 1357-1374

57. Shikama K (2006) Nature of the FeO2 bonding in myoglobin and hemoglobin: A new molecular paradigm. Prog Biophys Mol Biol 91: 83-162.

58. Kao OHW, Wang JH (1965) Kinetic study of the oxidation of ferrohemochrome by molecular oxygen. Biochemistry 4: 342-347.

59. Sugawara Y, Matsuoka A, Kaino A, Shikama K (1995) Role of globin moiety in the autoxidation reaction of oxymyoglobin: effect of $8 \mathrm{M}$ urea. Biophys $\mathrm{J} 69$ : 583-592.

60. Paul WD, Kemp CR (1944) Methemoglobin: A normal constituent of blood Proc Soc Exp Biol Med 56: 55-56

61. BODANSKY O (1951) Methemoglobinemia and methemoglobin-producing compounds. Pharmacol Rev 3: 144-196.

62. Tomoda A, Takeshita M, Yoneyama Y (1978) Characterization of intermediate hemoglobin produced during methemoglobin reduction by ascorbic acid. J Biol Chem 253: 7415-7419.

63. Tomoda A, Tsuji A, Matsukawa S, Takeshita M, Yoneyama Y (1978) Mechanism of methemoglobin reduction by ascorbic acid under anaerobic conditions. J Bio Chem 253: 7240-7243

64. Tomoda A, Yubisui T, Tsuji A, Yoneyama Y (1979) Kinetic studies on methemoglobin reduction by human red cell NADH cytochrome b5 reductase. J Biol Chem 254: 3119-3123.

65. Tomoda A, Imoto M, Hirano M, Yoneyama Y (1979) Analyis of met-form haemoglobins in human erythrocytes of normal adults and of a patient with hereditary methaemoglobinaemia due to deficiency of $\mathrm{NADH}$-cytochrome b5 reductase. Biochem J 181: 505-507.

66. Tomoda A, Tsuji A, Yoneyama Y (1980) Mechanism of hemoglobin oxidation by ferricytochrome $\mathrm{c}$ under aerobic and anaerobic conditions. J Biol Chem 255 7978-7983.

67. Tomoda A, Ida M, Tsuji A, Yoneyama Y (1980) Mechanism of methaemoglobin reduction by human erythrocytes. Biochem J 188: 535-540.

68. Park SY, Yokoyama T, Shibayama N, Shiro Y, Tame JR (2006) 1.25 A resolution crystal structures of human haemoglobin in the oxy, deoxy and carbonmonoxy forms. J Mol Biol 360: 690-701.

69. JANDL JH, ENGLE LK, ALLEN DW (1960) Oxidative hemolysis and precipitation of hemoglobin. I. Heinz body anemias as an acceleration of red cell aging. J Clin Invest 39: 1818-1836.

70. Peisach J, Blumberg WE, Rachmilewitz EA (1975) Detection of formation, and relevance of hemichromes and hemochromes. Biochim Biophys Acta 393: 404 418

71. Sears DA, Friedman JM, White DR (1975) Binding of intracellular protein to the erythrocyte membrane during incubation: the production of Heinz bodies. J Lab Clin Med 86: 722-732.

72. Campwala HQ, Desforges JF (1982) Membrane-bound hemichrome in densityseparated cohorts of normal (AA) and sickled (SS) cells. J Lab Clin Med 99 25-28.

73. Selwyn JG (1955) Heinz bodies in red cells after splenectomy and after phenacetin administration. Br J Haematol 1: 173-183.

74. Weiss L (1963) The Structure of Intermediate Vascular Pathways in the Spleen of Rabbits. Am J Anat 113: 51-91.

75. Wennberg E, Weiss L (1968) Splenic erythroclasia: an electron microscopic study of hemoglobin $\mathrm{H}$ disease. Blood 31: 778-790.

76. Phillips SE (1978) Structure of oxymyoglobin. Nature 273: 247-248

77. Vitagliano L, Bonomi G, Riccio A, di Prisco G, Smulevich G, et al. (2004) The oxidation process of Antarctic fish hemoglobins. Eur J Biochem 271: 1651 1659

78. Vergara A, Franzese M, Merlino A, Vitagliano L, Verde C, et al. (2007) Structura characterization of ferric hemoglobins from three antarctic fish species of the suborder notothenioidei. Biophys J 93: 2822-2829.

79. Vergara A, Franzese M, Merlino A, Bonomi G, Verde C, et al. (2009) Correlation between hemichrome stability and the root effect in tetramerichemoglobins. Biophys J 97: 866-874. 
Citation: Sugawara Y, Shigemasa Y, Hayashi Y, Abe Y, Ohgushi I, et al. (2013) New Mode (Molecular-Sensing) of Heinz Body Formation Mechanisms Inherent in Human Erythrocytes: Basis for Understanding of Clinical Aspects of Drug-Induced Hemolytic Anemia and the Like. J Bioanal Biomed 5: 036-056. doi:10.4172/1948-593X.1000078

80. Robinson VL, Smith BB, Arnone A (2003) A pH-dependent aquomet-tohemichrome transition in crystalline horse methemoglobin. Biochemistry 42 : 10113-10125.

81. Clark MR (1988) Senescence of red blood cells: progress and problems Physiol Rev 68: 503-554.

82. Low PS (1991) Role of Hemoglobin Denaturation and Band 3 Clustering in Initiating Red Cell Removal. In Red Blood Cell Aging; Magnani173-183.

83. Walder JA, Chatterjee R, Steck TL, Low PS, Musso GF, et al. (1984) The interaction of hemoglobin with the cytoplasmic domain of band 3 of the human erythrocyte membrane. J Biol Chem 259: 10238-10246.

84. Waugh SM, Low PS (1985) Hemichrome binding to band 3: nucleation of Heinz bodies on the erythrocyte membrane. Biochemistry 24: 34-39.

85. Low PS, Waugh SM, Zinke K, Drenckhahn D (1985) The role of hemoglobin denaturation and band 3 clustering in red blood cell aging. Science 227: 531533 .

86. Schlüter K, Drenckhahn D (1986) Co-clustering of denatured hemoglobin with band 3: its role in binding of autoantibodies against band 3 to abnormal and aged erythrocytes. Proc Natl Acad Sci U S A 83: 6137-6141.

87. Waugh SM, Walder JA, Low PS (1987) Partial characterization of the copolymerization reaction of erythrocyte membrane band 3 with hemichromes. Biochemistry 26: 1777-1783.

88. Zhang D, Kiyatkin A, Bolin JT, Low PS (2000) Crystallographic structure and functional interpretation of the cytoplasmic domain of erythrocyte membrane band 3. Blood 96: 2925-2933.

89. Van den Ende J, Coppens G, Verstraeten T, Van Haegenborgh T, Depraetere $\mathrm{K}$, et al. (1998) Recurrence of blackwater fever: triggering of relapses by different antimalarials. Trop Med Int Health 3: 632-639.

90. Mararia WJM (2003) In Manson's Tropical Diseases. Cook GC, ZumuraAI. Eds. W.B. Saunders: Philadelphia, USA 1205-1295.

91. Hue NT, Charlieu JP, Chau TT, Day N, Farrar JJ, et al. (2009) Glucose-6 phosphate dehydrogenase (G6PD) mutations and haemoglobinuria syndrome in the Vietnamese population. Malar J 8: 152. 